\title{
THz and mid-IR spectroscopy of interstellar ice analogs: methyl and carboxylic acid groups
}

\author{
S. Ioppolo, ${ }^{\text {*ab }}$ B. A. McGuire, $\uparrow^{c}$ M. A. Allodi $\dagger^{c}$ and G. A. Blake
}

Received 21st December 2013, Accepted 7th February 2014

DOI: $10.1039 / c 3 f d 00154 g$

A fundamental problem in astrochemistry concerns the synthesis and survival of complex organic molecules (COMs) throughout the process of star and planet formation. While it is generally accepted that most complex molecules and prebiotic species form in the solid phase on icy grain particles, a complete understanding of the formation pathways is still largely lacking. To take full advantage of the enormous number of available $\mathrm{THz}$ observations (e.g., Herschel Space Observatory, SOFIA, and ALMA), laboratory analogs must be studied systematically. Here, we present the $\mathrm{THz}\left(0.3-7.5 \mathrm{THz} ; 10-250 \mathrm{~cm}^{-1}\right.$ ) and mid-IR $\left(400-4000 \mathrm{~cm}^{-1}\right)$ spectra of astrophysically-relevant species that share the same functional groups, including formic acid $(\mathrm{HCOOH})$ and acetic acid $\left(\mathrm{CH}_{3} \mathrm{COOH}\right)$, and acetaldehyde $\left(\mathrm{CH}_{3} \mathrm{CHO}\right)$ and acetone $\left(\left(\mathrm{CH}_{3}\right)_{2} \mathrm{CO}\right)$, compared to more abundant interstellar molecules such as water $\left(\mathrm{H}_{2} \mathrm{O}\right)$, methanol $\left(\mathrm{CH}_{3} \mathrm{OH}\right)$, and carbon monoxide (CO). A suite of pure and mixed binary ices are discussed. The effects on the spectra due to the composition and the structure of the ice at different temperatures are shown. Our results demonstrate that $\mathrm{THz}$ spectra are sensitive to reversible and irreversible transformations within the ice caused by thermal processing, suggesting that $\mathrm{THz}$ spectra can be used to study the composition, structure, and thermal history of interstellar ices. Moreover, the $\mathrm{THz}$ spectrum of an individual species depends on the functional group(s) within that molecule. Thus, future $\mathrm{THz}$ studies of different functional groups will help in characterizing the chemistry and physics of the interstellar medium (ISM).

\section{Introduction}

Much astrochemical research in recent years has focused on understanding the chemical and physical pathways that potentially lead to the formation of biotic

${ }^{a}$ Division of Geological and Planetary Sciences, California Institute of Technology, 1200 E. California Blvd., Pasadena, CA 91125, USA. E-mail: ioppolo@caltech.edu; Fax: +1 (626) 568-0935; Tel: +1 (626) 395-6962 ${ }^{b}$ Institute for Molecules and Materials, Radboud University Nijmegen, PO Box 9010, Nijmegen, NL 6500 GL, The Netherlands

'Division of Chemistry and Chemical Engineering, California Institute of Technology, 1200 E. California Blvd., Pasadena, CA, 91125, USA

$\dagger$ These authors contributed equally to this work. 
and prebiotic molecules in the interstellar medium (ISM). This focus has only intensified with the detection of glycine, the simplest amino acid, in cometary samples recently returned by the STARDUST mission. ${ }^{\mathbf{1}}$ The quest to understand the possible cosmic origins of life as we know it is of great importance to the wider scientific community and in the eyes of the public at large. Therefore, the laboratory, modeling, and observational communities must work together to achieve this ambitious goal. Yet, despite having detected amino acids in meteorites and comets, we lack a complete understanding of the formation pathways for even these relatively simple prebiotic precursors.

For instance, recent laboratory experiments, corroborated by astrochemical models, strongly support the hypothesis that hydroxylamine $\left(\mathrm{NH}_{2} \mathrm{OH}\right)$, a possible precursor of glycine, is efficiently formed in the solid state under dense dark cloud conditions. ${ }^{2-6}$ Deep within dark interstellar clouds, where temperatures drop as low as $10 \mathrm{~K}$ and densities are on the order of $10^{5} \mathrm{~cm}^{-3}$, gas-phase species accrete onto grains, forming icy mantles. Interstellar grains act as a third body capable of carrying off the excess energy released from newly formed bonds, thus promoting surface reactions. During the early stages of star and planet formation, solid-state chemistry is largely dominated by barrierless reactions involving free atoms - H, D, C, N, and $\mathrm{O}$ - landing and diffusing on the ice surface of the grains. Later, energetic processing (e.g., heating, UV-irradiation) becomes important. In this scenario, $\mathrm{NH}_{2} \mathrm{OH}$ has been shown to be formed through the barrierless hydrogenation of $\mathrm{NO}$ and $\mathrm{NO}_{2}$. However, single-dish observations by Pulliam et al. ${ }^{7}$ failed to detect $\mathrm{NH}_{2} \mathrm{OH}$ in various warm astronomical environments. The non-detection of $\mathrm{NH}_{2} \mathrm{OH}$ can be explained by efficient photodissociation pathways or thermally-activated surface reactions within the ice.

Another relevant example is methyl formate $\left(\mathrm{HCOOCH}_{3}\right)$, an abundant molecule detected toward a plethora of interstellar sources (see, e.g., Nummelin et al. ${ }^{8}$ and refs. therein). Until the last decade, $\mathrm{HCOOCH}_{3}$, as well as most other complex organic molecules (COMs), was presumed to form primarily through gas-phase ion-molecule reactions. However, both experimental and theoretical work has shown that the reactions that were thought to give rise to $\mathrm{HCOOCH}_{3}$ are inefficient in the gas-phase. ${ }^{9}$ Instead, recent gas-grain chemical models have shown that $\mathrm{HCOOCH}_{3}$, and indeed many COMs, are likely to be formed from radicalradical and radical-neutral reactions on and within the icy mantles of dust grains (see, e.g., Garrod et al. ${ }^{10}$ and Garrod ${ }^{11}$ ). Often, these radicals are small organic functional groups (e.g. $\mathrm{CH}_{3}, \mathrm{OH}, \mathrm{NH}_{2}$, and $\mathrm{CHO}$ ) formed from the UV photodissociation of simpler organic species such as methanol $\left(\mathrm{CH}_{3} \mathrm{OH}\right)$ (see, e.g., Öberg et al., ${ }^{12}$ Laas et al. ${ }^{13}$ Laas et al. ${ }^{14}$ and refs. therein). This suggests that many observed COMs may share common formation pathways in these ices. Thus, examining sets of interstellar species which share common functional groups offers essential insight into how these species form in interstellar environments.

Mid-infrared (mid-IR) spectroscopy $\left(400-4000 \mathrm{~cm}^{-1}\right)$ has been fundamental in improving our understanding of ice and dust in the ISM over the past few decades. As a result, the most abundant simple molecules have been detected in the solid phase via mid-IR astronomical observations (see Öberg et al. ${ }^{15}$ for a review). However, transitions at IR frequencies correspond to intramolecular vibrational modes of the molecules in the ice. Therefore, complex species that share functional groups may present similar IR spectra with absorption features that overlap with each other and with those of the most abundant species in the 
solid phase (e.g., $\mathrm{H}_{2} \mathrm{O}, \mathrm{CO}, \mathrm{CO}_{2}, \mathrm{H}_{2} \mathrm{CO}, \mathrm{CH}_{3} \mathrm{OH}, \mathrm{CH}_{4}, \mathrm{HCOOH}$, and $\mathrm{NH}_{3}$ ). Mid-IR observations are also limited by the fact that we can observe solid-phase species only in absorption, rather than in emission, greatly limiting the sample set of astronomical sources.

In contrast, TeraHertz (THz), or far-IR, spectroscopy, covering the region from 0.1 to $10 \mathrm{THz}\left(3-330 \mathrm{~cm}^{-1}\right)$, directly probes lower frequency vibrations that correspond to low energy intra- and, especially, intermolecular modes. $\mathrm{THz}$ spectroscopy is therefore particularly sensitive to the long range interactions between molecules and allows for direct measurements of large-scale structural changes. ${ }^{16}$ Moreover, unlike the case in the mid-IR spectral region, at $\mathrm{THz}$ wavelengths, photon energies are sufficiently small, so temperatures less than $\sim 150 \mathrm{~K}$ can provide a detectable emission signal, and absorption can occur against the background continuum. Thus, THz spectroscopy provides the unique opportunity to detect ices in disks and clouds both in emission and in absorption against the widespread dust continuum, through a number of distinct features and, theoretically, along any line of sight.

To take full advantage of the enormous number of available $\mathrm{THz}$ observations (e.g., Herschel Space Observatory, SOFIA, and ALMA), laboratory analogs must be studied systematically. Some THz lab data on ices are presently available. ${ }^{17,18}$ Here, we present the $\mathrm{THz}$ and mid-IR spectra of perhaps the simplest series of astrophysically-relevant molecules which share common, and progressively more complex functional groups (see Fig. 1), as well as the abundant ice species $\mathrm{H}_{2} \mathrm{O}$, $\mathrm{CH}_{3} \mathrm{OH}$, and $\mathrm{CO}$.

\section{Experimental methods}

The experimental apparatus has been described in detail elsewhere. ${ }^{16}$ Briefly, a high-resistivity intrinsic Si substrate, located inside a high-vacuum chamber $(5 \times$ $10^{-6}$ Torr at $300 \mathrm{~K}$ ), is cooled to $\sim 8 \mathrm{~K}$ using a He-cooled cryostat. A heating coil can control the temperature of the substrate from $8 \mathrm{~K}$ to $300 \mathrm{~K}$. Gas samples are

Formic Acid<smiles></smiles><smiles>CCCC</smiles>

Formaldehyde

Acetic Acid<smiles>CC(=O)O</smiles><smiles>CC=O</smiles>

Acetaldehyde

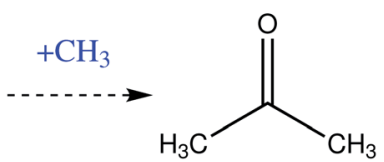

Acetone

Fig. 1 Cartoon demonstrating the increasing complexity achievable with the addition of a single functional group (in this case $\mathrm{OH}$ or $\mathrm{CH}_{3}$ radicals) to a simpler, neutral species. Arrows do not represent reaction pathways or mechanisms. 
prepared in a metal dosing line and deposited onto the Si substrate to form an ice via a capillary stainless steel pipe normal to the Si surface. The end of the pipe is capped with a metal mesh with a $38 \mu \mathrm{m}$ hole size to ensure a uniform, one-sided ice deposition. Transmission spectra can be collected in both the mid-IR from 400 to $4000 \mathrm{~cm}^{-1}$, and the THz from 0.3 to $8 \mathrm{THz}\left(10\right.$ to $\left.265 \mathrm{~cm}^{-1}\right)$. Mid-IR spectra were taken using a Nicolet 6700 FTIR spectrometer externally coupled to a mercurycadmium-telluride (MCT) detector. THz spectra were collected using a home-built time-domain (TD) THz spectrometer which is described in more detail below. The beams from the two spectrometers enter the vacuum chamber along separate paths and are incident on the substrate at $45^{\circ}$ relative to the surface. This configuration is chosen to allow for the simultaneous acquisition of THz and mid-IR spectra. Unless otherwise specified, 256 scans are co-added to produce an average when acquiring mid-IR spectra using the FTIR ( $\sim 10$ min of acquisition time), while 64 scans are coadded for the THz spectra ( $\sim 2 \mathrm{~h}$ of acquisition time). Each spectrum was ratioed with the background scan of a blank substrate held at $250 \mathrm{~K}$.

\subsection{THz instrumentation}

There have been some changes to the $\mathrm{THz}$ spectrometer since the publication of Allodi et $a .^{16}$ (see Fig. 2). The output of the ultrafast regenerative amplifier (Legend Elite, Coherent Inc.) seeds an optical parametric amplifier (OPA) (Light Conversion Inc. TOPAS-C) capable of generating $<40 \mathrm{fs}$ pulses in the near-IR. Taking the idler output of the OPA at $1745 \mathrm{~nm}$, and focusing that beam through a beta-barium borate (BBO) crystal creates the two-color plasma needed for $\mathrm{THz}$ pulse generation. This plasma generates $\mathrm{THz}$ pulses in a similar manner to the two-color plasma created with an $800 \mathrm{~nm}$ pulse and its second harmonic; however, the THz generation mechanism in plasma is more efficient. ${ }^{19}$ Previously, pulses with roughly $3.5 \mathrm{~mJ}$ of energy at $800 \mathrm{~nm}$ created a plasma to generate $\mathrm{THz}$ pulses. Now, pulses with roughly $350 \mu \mathrm{J}$ of energy at $1745 \mathrm{~nm}$ generate a plasma that produces $\mathrm{THz}$ pulses with a power comparable to the previous plasma at $800 \mathrm{~nm}$. The wavelength of $1745 \mathrm{~nm}$ was chosen because it provided the largest peak $\mathrm{THz}$ electric fields for the current optical alignment of the spectrometer.

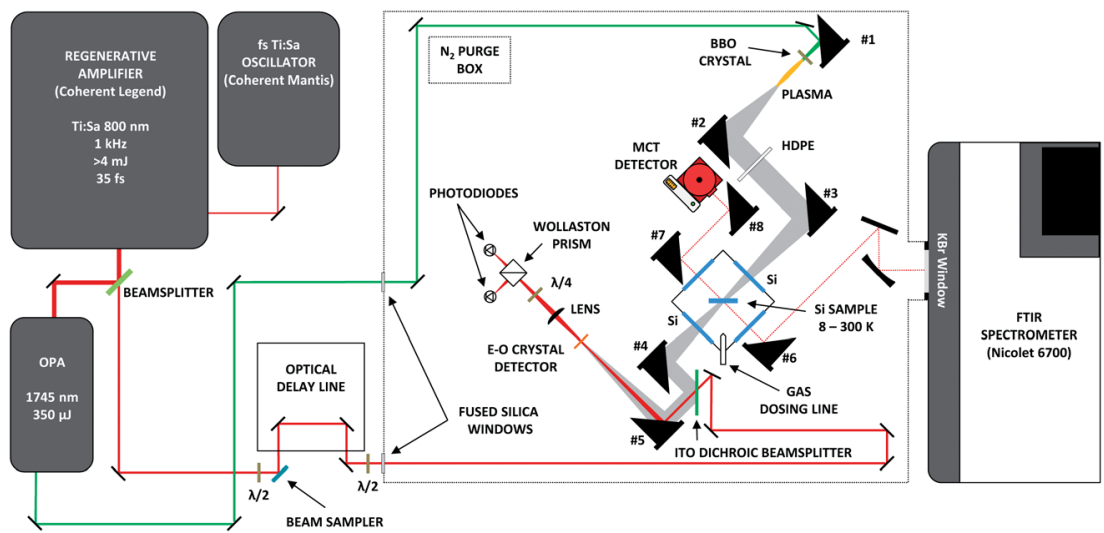

Fig. 2 Schematic of the Caltech astronomical ice analog experimental setup, including the home-build time domain $\mathrm{THz}$ spectrometer (not to scale). 
The THz field is detected via Electro-optic (EO) sampling in a GaP crystal (Del Mar Photonics Inc.) using a small percentage of the output of the ultrafast amplifier at $800 \mathrm{~nm}$ that is not used to seed the OPA. This crystal is different from the one used by Allodi et al. ${ }^{16}$ in that it has a thin EO active layer optically contacted to a thicker inactive layer. Specifically, a GaP (110) layer $200 \mu \mathrm{m}$ thick, and capable of EO sampling, is optically contacted to a GaP (100) layer $4 \mathrm{~mm}$ thick that is EO inactive. This provides the advantage of pushing etalon features, or recurrences of the pulse in the time domain, outside the window being scanned. This ensures that any changes between the sample scan and the reference scan in the time domain will not lead to artificial signals in the frequency domain.

\subsection{Data processing}

The THz waveforms were collected over a 12 ps window in the time domain, starting 3 ps before the THz peak and continuing until 9 ps after the THz peak. A lock-in amplifier (Stanford Research Systems SR830) set for a $100 \mathrm{~ms}$ time constant was used to acquire the THz signals, which are modulated by an optical chopper set to $500 \mathrm{~Hz}$. The waveforms contain 119.92 points per ps to ensure adequate sampling of the frequency content from 0.3 to $8 \mathrm{THz}$. Absorption spectra of the samples studied in the frequency domain are found by taking a fast Fourier transform (FFT) of the time domain data and dividing by a reference scan of the bare Si substrate.

The resolution of the spectra collected is approximately equal to the inverse of the length of scan in the time domain. For these experiments, this yields a $\sim 90$ $\mathrm{GHz}$ resolution in the frequency domain. With the optically contacted GaP crystal described in the section above, it is possible to increase the resolution of these spectra on our instrument to $\sim 10 \mathrm{GHz}$ by scanning a larger window in the time domain. However, this time window was chosen so as to quickly collect high signal-to-noise spectra of many different ices. The following data analysis procedure allows us to extract the maximum information from the collected data.

Apodization of the time-domain data prevents noise from spectral leakage. When Fourier transforming a time-domain signal collected in a window of finite duration, a boxcar function becomes convolved with the true time-domain signal, resulting in each line in the frequency domain being convolved with a sinc function. ${ }^{20}$ Spectral leakage arises because a sinc function will add many sidelobes to the main peak, and so distinguishing between separate peaks becomes more difficult. Choosing a different apodization function from the boxcar will suppress the sidelobes and prevent spectral leakage that would arise from the sidelobes of one feature overlapping with the peak of another nearby feature. However, there is a balance to be struck between suppressing the sidelobes, but not distorting the lineshape drastically. In addition, asymmetric apodization functions must be used given the asymmetric nature of the $\mathrm{THz}$ signal in the collection window. ${ }^{21}$ All the data in this paper are processed using an asymmetric Hann window peaked at the maximum of the THz signal. The Hann window ${ }^{22}$ provides a good balance between sidelobe suppression and lineshape concerns.

After apodization, zeros were added to the apodized data to both interpolate between points in the frequency domain and ensure that the length of the data set equals a power of two. Zero padding in the time domain before taking an FFT is mathematically identical to interpolation in the frequency domain. ${ }^{23}$ 
Interpolation can help to identify the center of a feature with high accuracy. This can be especially useful for high signal-to-noise data since increasing the signalto-noise ratio increases the accuracy of the measurement of peak centers. In addition to interpolation, zero padding to create a data set of length $2^{N}$, where $N$ is a positive integer, maximizes the speed of the FFT calculation.

\subsection{Computational methodology}

$A b$ Initio quantum chemical calculations were performed on dimers of formic acid and acetic acid molecules to provide a molecular interpretation of some of the unassigned modes present in the $\mathrm{THz}$ spectral region as shown and discussed in the next sections. All calculations were performed using the MP2/6-311+G(d,p) level of theory to adequately model the hydrogen-bonding interactions between molecules and were carried out using Gaussian 09. ${ }^{24}$ Since harmonic frequencies calculated with MP2 are known to be systematically biased toward higher frequencies than are observed, ${ }^{25}$ the calculated frequencies in wavenumbers are scaled by a value of 0.9646 as used by Pople et al. ${ }^{26}$

\section{Results}

A listing of the mid-IR and THz spectra of simple and more complex pure ices, as well as some selected mixtures, are presented in Table 1 . The water used for the ice samples is deionized and purified (Milli-Q water purifier, EMD Millipore) before being degassed by several freeze-pump-thaw cycles. In general, all the liquid samples used in this work $\left(\mathrm{CH}_{3} \mathrm{OH}\right.$ from Omni Solv 99.9\%, $\mathrm{HCOOH}$ from Sigma Aldrich 98-100\%, $\mathrm{CH}_{3} \mathrm{CHO}$ from Fluka/Sigma Aldrich 99.5\%, $\mathrm{CH}_{3} \mathrm{COOH}$ from J. T. Baker $99.7 \%$, and $\left(\mathrm{CH}_{3}\right)_{2} \mathrm{CO}$ from Macron Chemicals $99.5 \%$ ) are degassed by freeze-pump-thaw cycles. Gaseous CO is used as received from Air Liquide $(99.97 \%)$.

Crystalline ices are deposited close to their desorption temperature under our experimental conditions, while all the amorphous ices are formed at $10 \mathrm{~K}$. After deposition, crystalline ices are cooled down in temperature, while amorphous ices are generally heated or annealed to higher temperatures as shown in Table 1. Our selected crystalline and amorphous films are in all cases less than $10 \mu \mathrm{m}$ thick and are generally condensed at a rate of $\sim 30 \mu \mathrm{m} \mathrm{hr}^{-1}$.

\subsection{Mid-IR spectra of selected pure ices}

Fig. 3 shows the mid-IR crystalline spectra of the species investigated in this work. All the spectra are acquired during deposition to obtain non-saturated IR absorption bands. Here, 64 scans are generally co-added to produce a non-saturated spectrum.

$\mathbf{H}_{2}$ O. Fig. 3 shows a typical mid-IR spectrum of cubic-crystalline water ice deposited at $140 \mathrm{~K}^{27-29}$ The water IR spectrum exhibits four broad bands between 400 and $4000 \mathrm{~cm}^{-1}$ : (i) the libration of water molecules at $12.5 \mu \mathrm{m}\left(800 \mathrm{~cm}^{-1}\right) ;(i i)$ the bending mode at $\sim 6 \mu \mathrm{m}\left(1650 \mathrm{~cm}^{-1}\right)$; (iii) a combination band at $4.5 \mu \mathrm{m}$ $\left(2200 \mathrm{~cm}^{-1}\right)$; $(i v)$ and the $\mathrm{OH}$-stretching mode at $\sim 3 \mu \mathrm{m}\left(3250 \mathrm{~cm}^{-1}\right)$. Peak position and band profile of these bands are strongly dependent on the type of ice (amorphous $v s$. crystalline) and on thermal history of the ice as will be discussed in more detail later in the text. 
Table 1 List of experiments performed in this work

\begin{tabular}{|c|c|c|c|}
\hline Experiment & Ratio & $T_{\mathrm{dep}} / \mathrm{K}$ & Thermal History/K \\
\hline \multicolumn{4}{|l|}{ Pure ice } \\
\hline $\mathrm{H}_{2} \mathrm{O}$ & & 175 & 140,10 \\
\hline $\mathrm{H}_{2} \mathrm{O}$ & & 150 & $150,75,10$ \\
\hline $\mathrm{H}_{2} \mathrm{O}$ & & 140 & $140,75,10,10^{a}$ \\
\hline $\mathrm{H}_{2} \mathrm{O}$ & & 140 & 10 \\
\hline $\mathrm{H}_{2} \mathrm{O}$ & & 125 & 10 \\
\hline $\mathrm{H}_{2} \mathrm{O}$ & & 10 & $10,125,150$ \\
\hline $\mathrm{CO}$ & & 30 & 25,10 \\
\hline $\mathrm{CO}$ & & 30 & 10 \\
\hline $\mathrm{CO}$ & & 10 & $10,25^{b}$ \\
\hline $\mathrm{CH}_{3} \mathrm{OH}$ & & 140 & $100,75,10$ \\
\hline $\mathrm{CH}_{3} \mathrm{OH}$ & & 140 & $100,75,10$ \\
\hline $\mathrm{CH}_{3} \mathrm{OH}$ & & 10 & $10,75,100^{c}$ \\
\hline $\mathrm{HCOOH}$ & & 150 & $100,75,10$ \\
\hline $\mathrm{HCOOH}$ & & 10 & $10,75,75^{d}, 10$ \\
\hline $\mathrm{CH}_{3} \mathrm{CHO}$ & & 125 & $100,75,10$ \\
\hline $\mathrm{CH}_{3} \mathrm{CHO}$ & & 125 & $10,10,10$ \\
\hline $\mathrm{CH}_{3} \mathrm{CHO}$ & & 10 & $10,75,100,100^{e}$ \\
\hline $\mathrm{CH}_{3} \mathrm{CHO}$ & & 10 & $10,40,60,80,10^{e}$ \\
\hline $\mathrm{CH}_{3} \mathrm{COOH}$ & & 150 & $100,75,10$ \\
\hline $\mathrm{CH}_{3} \mathrm{COOH}$ & & 180 & $100,75,10$ \\
\hline $\mathrm{CH}_{3} \mathrm{COOH}$ & & 180 & $100,75,10$ \\
\hline $\mathrm{CH}_{3} \mathrm{COOH}$ & & 10 & $10,75,100,100^{f}$ \\
\hline$\left(\mathrm{CH}_{3}\right)_{2} \mathrm{CO}$ & & 150 & $100,75,10$ \\
\hline$\left(\mathrm{CH}_{3}\right)_{2} \mathrm{CO}$ & & 10 & $10,75,100$ \\
\hline$\left(\mathrm{CH}_{3}\right)_{2} \mathrm{CO}$ & & 10 & $10,75,100,100^{d}$ \\
\hline \multicolumn{4}{|l|}{ Mixed ice } \\
\hline $\mathrm{H}_{2} \mathrm{O}: \mathrm{CH}_{3} \mathrm{OH}$ & $2: 1$ & 140 & 10 \\
\hline $\mathrm{H}_{2} \mathrm{O}: \mathrm{CH}_{3} \mathrm{OH}$ & $1: 1$ & 140 & 10 \\
\hline $\mathrm{H}_{2} \mathrm{O}: \mathrm{CH}_{3} \mathrm{OH}$ & $0.5: 1$ & 140 & 10 \\
\hline $\mathrm{H}_{2} \mathrm{O}: \mathrm{CH}_{3} \mathrm{CHO}$ & $2: 1$ & 125 & 10 \\
\hline $\mathrm{H}_{2} \mathrm{O}: \mathrm{CH}_{3} \mathrm{CHO}$ & $1: 1$ & 125 & 10 \\
\hline $\mathrm{H}_{2} \mathrm{O}: \mathrm{CH}_{3} \mathrm{CHO}$ & $0.5: 1$ & 125 & 10 \\
\hline $\mathrm{H}_{2} \mathrm{O}:\left(\mathrm{CH}_{3}\right)_{2} \mathrm{CO}$ & $2: 1$ & 150 & 10 \\
\hline $\mathrm{H}_{2} \mathrm{O}:\left(\mathrm{CH}_{3}\right)_{2} \mathrm{CO}$ & $1: 1$ & 150 & 10 \\
\hline $\mathrm{H}_{2} \mathrm{O}:\left(\mathrm{CH}_{3}\right)_{2} \mathrm{CO}$ & $0.5: 1$ & 150 & 10 \\
\hline \multicolumn{4}{|c|}{$\begin{array}{l}{ }^{a} \text { Annealed to } 175 \mathrm{~K} \text { for } 10 \mathrm{~min} .{ }^{b} \text { Annealed to } 32 \mathrm{~K} \text { for } 5 \mathrm{~min} .{ }^{c} \text { Annealed to } 140 \mathrm{~K} \text { for } 10 \mathrm{~min} \\
\text { and } 145 \mathrm{~K} \text { for }<1 \mathrm{~min}{ }^{d} \text { Annealed to } 150 \mathrm{~K} \text { for } 10 \mathrm{~min} .{ }^{e} \text { Annealed to } 125 \mathrm{~K} \text { for } 5 \mathrm{~min} \text {. } \\
{ }^{f} \text { Annealed to } 200 \mathrm{~K} \text { for } 5 \mathrm{~min} \text {; } T_{\mathrm{dep}} \text { is the substrate temperature during deposition; } \\
\text { Thermal History notes the temperatures that the ice have been sequentially exposed to. } \\
\text { The heating ramp rate is in all cases } 20 \mathrm{~K} \mathrm{~min}^{-1} \text {. }\end{array}$} \\
\hline
\end{tabular}

CO. The spectrum of $\mathrm{CO}$ ice deposited at $30 \mathrm{~K}$ is largely flat with one strong absorption feature at $4.6 \mu \mathrm{m}\left(2140 \mathrm{~cm}^{-1}\right) .{ }^{13} \mathrm{CO}$ is also present in the ice as a small fraction of the total ${ }^{12} \mathrm{CO}$ according to its ${ }^{13} \mathrm{C} \equiv \mathrm{O}$ stretch mode band visible in Fig. 3 at $4.8 \mu \mathrm{m}\left(2090 \mathrm{~cm}^{-1}\right)$.

$\mathbf{C H}_{3} \mathbf{O H}$. Methanol, the final ice mantle product created by the hydrogenation of CO ice, has a somewhat more complex mid-IR spectrum than its precursor: $(i)$ a torsion mode at $4.8 \mu \mathrm{m}\left(710 \mathrm{~cm}^{-1}\right)$; (ii) the strong CO-stretch at $9.7 \mu \mathrm{m}$ $\left(1030 \mathrm{~cm}^{-1}\right)$; (iii) the $\mathrm{CH}_{3}$-rock at $8.8 \mu \mathrm{m}\left(1130 \mathrm{~cm}^{-1}\right)$; (iv) the $\mathrm{OH}$-bend at $\sim 7 \mu \mathrm{m}$ 


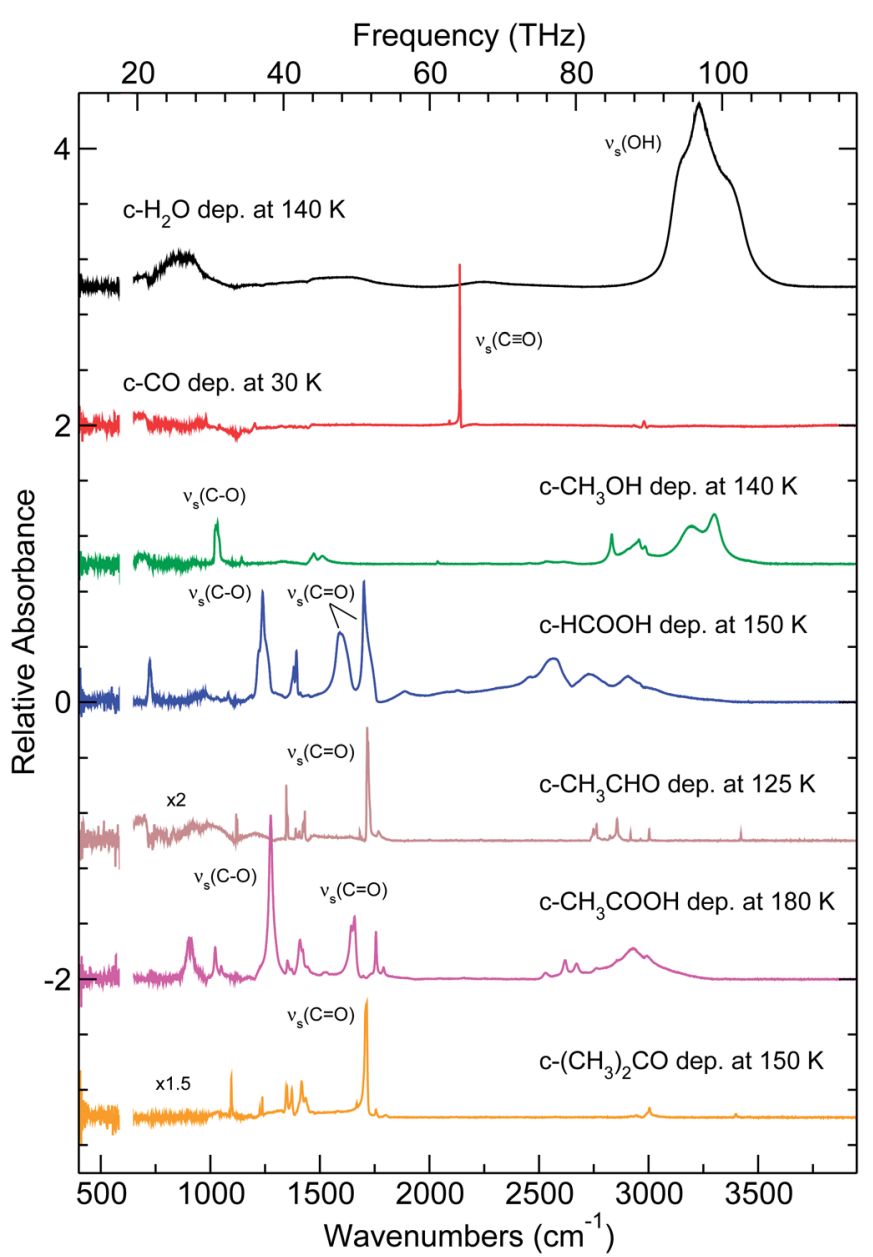

Fig. 3 Mid-IR FTIR spectra of non-saturated crystalline pure ices. Spectra are acquired during deposition of thicker ices. The strongest vibrational modes are assigned in the figure.

$\left(1415 \mathrm{~cm}^{-1}\right)$; (v) the $\mathrm{CH}_{3}$-deformation at $6.8 \mu \mathrm{m}\left(1470 \mathrm{~cm}^{-1}\right)$; $(v i)$ a series of $\mathrm{CH}^{-}$ stretch modes between 3.5 and $3.3 \mu \mathrm{m}$ (2800 and $3000 \mathrm{~cm}^{-1}$ ); (vii) $\mathrm{OH}$-stretch mode at $\sim 3 \mu \mathrm{m}\left(3300 \mathrm{~cm}^{-1}\right) .^{30,31}$

HCOOH. Pure HCOOH deposited at $150 \mathrm{~K}$ presents several absorption bands in the mid-IR: ( $i)$ the OCO-bend mode at $14.2 \mu \mathrm{m}\left(700 \mathrm{~cm}^{-1}\right)$; (ii) a OH-bend mode at $10.7 \mu \mathrm{m}\left(930 \mathrm{~cm}^{-1}\right)$; (iii) the $\mathrm{CH}$-bend mode at $9.3 \mu \mathrm{m}\left(1070 \mathrm{~cm}^{-1}\right)$; $(i v)$ the strong C-O stretching mode at $8.3 \mu \mathrm{m}\left(1210 \mathrm{~cm}^{-1}\right)$; (v) the $\mathrm{OH}$-bend and the $\mathrm{CH}-$ bend modes at $7.2 \mu \mathrm{m}\left(1390 \mathrm{~cm}^{-1}\right)$; (vi) two strong $\mathrm{C}=\mathrm{O}$ stretching modes at 6 and $5.8 \mu \mathrm{m}$ (1650 and $\left.1715 \mathrm{~cm}^{-1}\right)$; (vii) and several $\mathrm{OH}$-stretch modes and a $\mathrm{CH}^{-}$ stretch mode in the spectral region between 3.9 and $3.2 \mu \mathrm{m}$ (2500 and $\left.3100 \mathrm{~cm}^{-1}\right) .^{32}$

$\mathbf{C H}_{3} \mathbf{C H O}$. Crystalline acetaldehyde deposited at $125 \mathrm{~K}$ has several sharp peaks in the mid-IR: $(i)$ the $\mathrm{CH}_{3}$-rock at $9 \mu \mathrm{m}\left(1115 \mathrm{~cm}^{-1}\right)$; (ii) the symmetric $\mathrm{CH}_{3}$ deformation at $7.4 \mu \mathrm{m}\left(1350 \mathrm{~cm}^{-1}\right)$; (iii) the in-plane $\mathrm{CH}$ wag at $7.1 \mu \mathrm{m}(1400$ 
$\left.\mathrm{cm}^{-1}\right)$; (iv) the asymmetric $\mathrm{CH}_{3}$ deformation at $7 \mu \mathrm{m}\left(1430 \mathrm{~cm}^{-1}\right)$; $(v)$ the COstretch at $5.8 \mu \mathrm{m}\left(1710 \mathrm{~cm}^{-1}\right)$; (vi) the carbonyl $\mathrm{CH}$-stretch at $3.7 \mu \mathrm{m}\left(2710 \mathrm{~cm}^{-1}\right)$; (vii) and a series of methyl CH-stretch between 3.4 and $2.7 \mu \mathrm{m}$ (2900 and $\left.3600 \mathrm{~cm}^{-1}\right) .^{33}$

$\mathbf{C H}_{3} \mathbf{C O O H}$. Acetic acid has a desorption temperature higher than water. Therefore, we deposited acetic acid at $180 \mathrm{~K}$ to obtain a crystalline film. Acetic acid presents a forest of features in the mid-IR. Thus, here we name only the strongest absorption bands shown in Fig. 3: $(i)$ the $\gamma(\mathrm{OH})$ at $10.8 \mu \mathrm{m}\left(920 \mathrm{~cm}^{-1}\right)$; (ii) the $\rho\left(\mathrm{CH}_{3}\right)$ at $9.5 \mu \mathrm{m}\left(1050 \mathrm{~cm}^{-1}\right)$; (iii) the very strong $\mathrm{C}-\mathrm{O}$ stretching mode at $7.7 \mu \mathrm{m}$ $\left(1300 \mathrm{~cm}^{-1}\right) ;(i v)$ the $\mathrm{OH}$ at $7.1 \mu \mathrm{m}\left(1410 \mathrm{~cm}^{-1}\right) ;(v)$ the $\mathrm{C}=\mathrm{O}$ stretching mode at 6 $\mu \mathrm{m}\left(1650 \mathrm{~cm}^{-1}\right)$; (vi) a combination mode at $3.7 \mu \mathrm{m}\left(2650 \mathrm{~cm}^{-1}\right)$; (vii) and the $\mathrm{OH}^{-}$ stretch at $3.4 \mu \mathrm{m}\left(2900 \mathrm{~cm}^{-1}\right) .{ }^{34}$

$\left(\mathbf{C H}_{3}\right)_{2} \mathbf{C O}$. Acetone deposited at $150 \mathrm{~K}$ has several absorption bands, among the more prominent are: $(i)$ the $\mathrm{CH}_{3}$-rock at $9.1 \mu \mathrm{m}\left(1090 \mathrm{~cm}^{-1}\right)$; (ii) the CC-stretch at $8.2 \mu \mathrm{m}\left(1210 \mathrm{~cm}^{-1}\right)$; (iii) a series of $\mathrm{CH}_{3}$ deformation modes between 7.4 and 6.6 $\mu \mathrm{m}\left(1350\right.$ and $\left.1500 \mathrm{~cm}^{-1}\right)$; (iv) the CO-stretch at $5.8 \mu \mathrm{m}\left(1710 \mathrm{~cm}^{-1}\right) ;(v)$ and the $\mathrm{CH}$-stretch at $3.3 \mu \mathrm{m}\left(3000 \mathrm{~cm}^{-1}\right) .{ }^{30}$

Fig. 3 clearly shows that molecules that share the same functional group present similar mid-IR absorption features (e.g., similar intramolecular vibrations). For instance, acetaldehyde and acetone have the methyl group in common and show almost identical IR features; formic acid and acetic acid share the carboxylic acid group and have similar IR spectra as well. This can be potentially a cause of spectral confusion when mixtures of species containing the same functional groups are investigated in the mid-IR.

The THz spectral range is dominated by intermolecular forces (lattice modes). These modes involve the relative motion of molecules as a whole and can be either translational or librational modes, and are therefore sensitive to the structure of the hydrogen bond network in general and the nature of the unit cell in particular for crystalline solids. Moreover, THz features often give information on the lattice of the ice or transitions between different phases (e.g., amorphous vs. crystalline). ${ }^{18}$ Therefore, $\mathrm{THz}$ spectroscopy can potentially give more information on the long range structure of the ice than mid-IR spectroscopy does, especially when pure ices of complex species or complex mixtures are investigated. In the next section, we present the THz spectra of the ices shown in Fig. 3. Because the intermolecular modes potentially involve many monomers, and are distinct for various topological combinations of the individual molecules, theoretical predictions of the resulting $\mathrm{THz}$ spectra are much more involved than are those for mid-infrared spectra. To date, little such work has been performed on species beyond water and $\mathrm{CO} / \mathrm{CO}_{2}$, and so the following discussion is necessarily qualitative.

\subsection{THz spectra of selected pure ices}

Fig. 4 shows some selected crystalline (left panel) and amorphous (right panel) pure ices in the spectral region between 0.3 and $7.5 \mathrm{THz}$. Although crystalline ices are deposited at temperatures close to the desorption temperature of each species, all the spectra shown in Fig. 4 are acquired at $10 \mathrm{~K}$. Moore and Hudson ${ }^{18}$ studied the $\mathrm{THz}$ spectra of crystalline and amorphous pure water, carbon monoxide, and methanol ices at $13 \mathrm{~K}$ in the spectral range between 3 and $15 \mathrm{THz}$ 


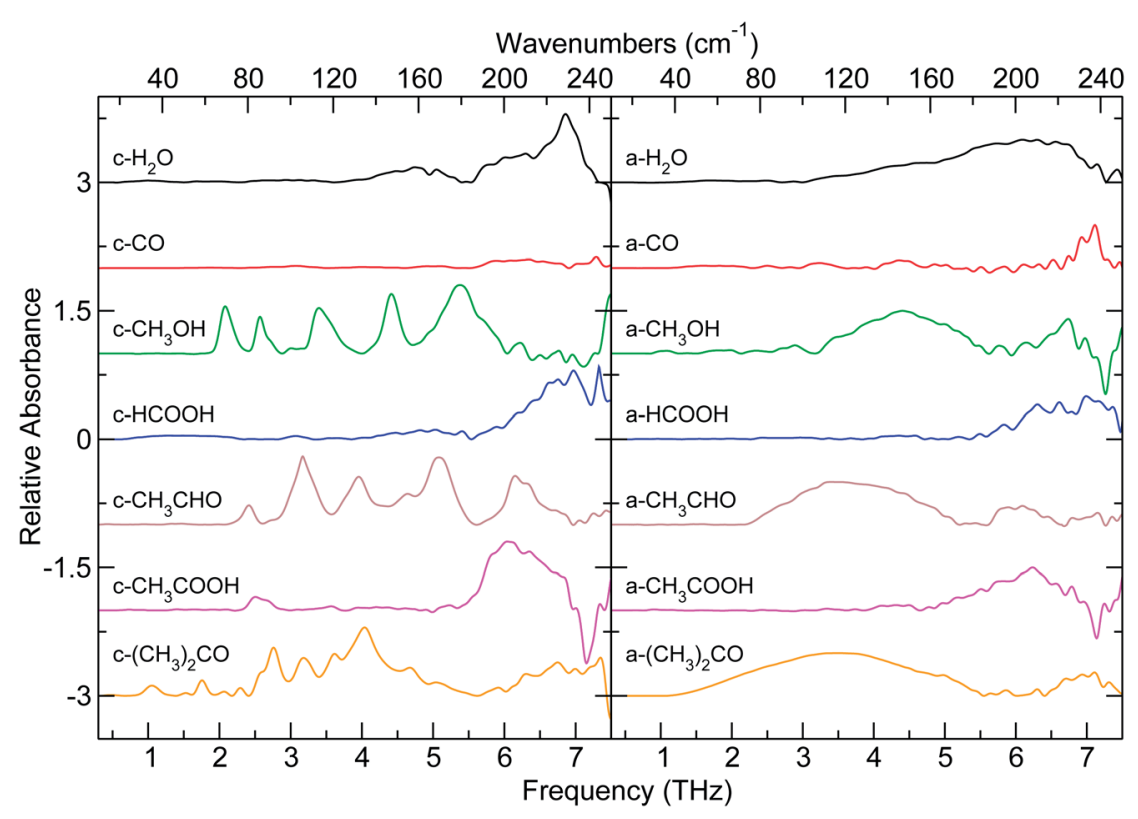

Fig. $4 \mathrm{THz}$ spectra of selected crystalline (left panel) and amorphous (right panel) pure ices. Although crystalline ices are deposited at higher temperatures, all the spectra are acquired at $10 \mathrm{~K}$.

by means of a standard FTIR technique. In their study, crystalline samples were formed by annealing ices that were pre-deposited at $13 \mathrm{~K}$. Our results are in good agreement with those from Moore and Hudson, ${ }^{18}$ i.e., peak position and band profiles are consistent with those found in literature. In general, amorphous features are found to be few, very broad, and strong, while crystalline bands are numerous, narrow, and often very strong. One of the novelties of our work is that the spectra shown in Fig. 4 include a spectral region that was not previously covered by FTIR techniques (i.e., between 0.3 and $3 \mathrm{THz}$ ). In this region, several new features are identified (see below). Moreover, our work includes a series of species never investigated in the THz range: $\mathrm{HCOOH}, \mathrm{CH}_{3} \mathrm{CHO}, \mathrm{CH}_{3} \mathrm{COOH}$, and $\left(\mathrm{CH}_{3}\right)_{2} \mathrm{CO}$.

$\mathbf{H}_{2} \mathbf{O}$. The THz spectrum of water ice is the most studied in the literature. ${ }^{\mathbf{1 8 , 3 5 - 3 7}}$ Amorphous water ice presents a strong and very broad band peaked at $6.2 \mathrm{THz}$, and a second broad band at $4.6 \mathrm{THz}$ that is a shoulder of the previous one. Other features are all very weak. Crystalline water ice deposited at $140 \mathrm{~K}$ and cooled to 10 K presents distinct peaks at 6.9 THz (H-bond stretch between bilayers), $5.7 \mathrm{THz}$ (out-of-phase vibration within a bilayer), $4.9 \mathrm{THz}$ (proton disordered motion), 4.3 $\mathrm{THz}, 1.9 \mathrm{THz}$ (corresponding to an $\mathrm{O}-\mathrm{O}-\mathrm{O}$ bend), and $1 \mathrm{THz}$ (as assigned in one of our previous works). ${ }^{16,38,39}$

CO. The THz spectrum of CO is nearly flat. ${ }^{18}$ The spectrum of crystalline CO deposited at $30 \mathrm{~K}$ and cooled to $10 \mathrm{~K}$ indicates that there may be a very weak and broad feature between 6 and $7 \mathrm{THz}$. The amorphous spectrum of CO at $10 \mathrm{~K}$ shows very weak peaks at 3 and $4.5 \mathrm{THz}$. The presence of weak features cannot be due to contaminations since the mid-IR spectra of $\mathrm{CO}$ ice do not show the presence of major impurities. Our THz-TD spectra are less sensitive to thin ices than the mid- 
IR FTIR measurements are. The stronger peak at 7.3 THz in the amorphous spectrum could be due to baseline subtraction artifacts. At those frequencies, the signal-to-noise ratio is quite low and a flat spectrum is therefore harder to reduce than a spectrum with clear $\mathrm{THz}$ features.

$\mathbf{C H}_{3} \mathbf{O H}$. Amorphous methanol shows a broad feature at $4.4 \mathrm{THz}$ and perhaps the beginning of another broad band at $6.8 \mathrm{THz}$ as also suggested in Ref. 18. Apart from the three peaks $(5.4,4.4$, and $3.4 \mathrm{THz}$ ) shown in Ref. 18, crystalline methanol deposited at $140 \mathrm{~K}$ and cooled to $10 \mathrm{~K}$ presents two other strong and sharp peaks at 2.6 and $2.1 \mathrm{THz}$. These peaks have not been reported before.

$\mathbf{H C O O H}$. Although the mid-IR spectrum of formic acid is quite complex with a forest of bands in absorption, the THz spectrum looks quite flat. Amorphous and crystalline formic acid have only a broad and strong band at $\sim 7 \mathrm{THz}$. The crystalline spectrum deposited at $150 \mathrm{~K}$ and cooled to $10 \mathrm{~K}$ shows some very weak features at lower frequencies, while the strong band is blue-shifted compared to the amorphous case.

$\mathbf{C H}_{3}$ CHO. Similar to methanol, amorphous acetaldehyde displays a broad band at 3.5 THz and a smaller one at $6 \mathrm{THz}$. Crystalline acetaldehyde deposited at $125 \mathrm{~K}$ and cooled at $10 \mathrm{~K}$ present several strong peaks at $6.2,5.1,4,3.2$, and 2.4 THz.

$\mathbf{C H}_{3} \mathbf{C O O H}$. As for formic acid, acetic acid spectra are quite flat except for a strong band at $\sim 6 \mathrm{THz}$. Crystalline acetic acid has also another band at $2.5 \mathrm{THz}$. As opposed to the other species studied here, acetic acid desorbs above the desorption temperature of water ice and therefore acetic acid is deposited crystalline at $180 \mathrm{~K}$ in this work.

$\left(\mathbf{C H}_{3}\right)_{2} \mathbf{C O}$. Crystalline acetone has perhaps the most complex $\mathrm{THz}$ spectrum studied here. Small and sharp bands are visible even at low frequencies where the other molecules do not have any absorption bands. There are two strong peaks at 4 and $2.8 \mathrm{THz}$. The other numerous bands are medium or weak. Amorphous acetone has a strong broad band at 3.5 and another band at $7 \mathrm{THz}$.

The THz spectra of pure methanol, acetaldehyde, and acetone are quite similar: the amorphous spectra all have a broad and strong band and a second broad band at higher frequencies; those bands split in several distinct features in the crystalline spectra of those molecules cooled at $10 \mathrm{~K}$. All the bands are strong and sharp. However, they do not perfectly overlap with each other. Formic acid and acetic acid present several spectral similarities as well: the spectra are generally quite flat, both amorphous and crystalline, and have a strong and broad feature around $7 \mathrm{THz}$. This may result from the strong dimer interactions expected for these species where a cyclic hydrogen bonded geometry is expected in both the gas and solid state. Finally, as noted above, the THz spectra of different molecules do not exactly overlap with each other. Thus, THz features can potentially provide a unique fingerprint of certain ice structures and compositions.

\subsection{The structure effect: the case of water ice}

Fig. 5 shows the full spectral range of our current setup (from 0.3 to $120 \mathrm{THz}$ or 10 to $4000 \mathrm{~cm}^{-1}$ with a few gaps). We plot water ice data here as example since it is the best studied and understood at both mid-IR and THz wavelengths. As is true for the other species in this work, the intermolecular forces and hydrogen-bonded network that characterizes solid state water enables a series of reversible and 
irreversible transformations to be accessed at low temperature. Allodi et al. ${ }^{\mathbf{1 6}}$ showed that crystalline water ices subjected to different temperature cycles present the same spectral profile in the $\mathrm{THz}$ at the same temperatures. This is an example of reversible transformation. However, when amorphous water ice is heated to higher temperatures the ice goes through a series of irreversible transformations such as the transition between amorphous solid porous water and amorphous solid compact water (above $\sim 100 \mathrm{~K}$ ), or amorphous solid compact water and crystalline water. However, crystallization of an annealed ice has been proven to be not completed even above $140 \mathrm{~K}^{29}$

Fig. 5 investigates the degree of crystallization of the water ice deposited at 175 , 140,125 , and $10 \mathrm{~K}$, respectively. Here, THz data clearly show substantial differences under different conditions. All the spectra are cooled to $10 \mathrm{~K}$ to better compare them with each other. The spectrum deposited at $175 \mathrm{~K}$ shows the full crystallization of the ice with the strongest H-bond stretch between bilayers at 6.9 THz. At $140 \mathrm{~K}$, water is clearly crystalline but a small fraction of it is still amorphous. At $125 \mathrm{~K}$, water shows the first signs of reorganization with a distinct separation between the bands at 4.9 and $6.9 \mathrm{THz}$, and a sharp tip at $6.8 \mathrm{THz}$. For comparison a spectrum of water ice deposited at $10 \mathrm{~K}$ is also shown. Mid-IR spectra show differences from each other, however, the $\mathrm{THz}$ range gives more direct signs of the transformation within the ice.

\subsection{The temperature effect: crystalline ices}

Allodi et $a l .{ }^{16}$ showed that the THz band profiles are temperature dependent in the case of crystalline water ice. Here we extend this to all the species studied in this

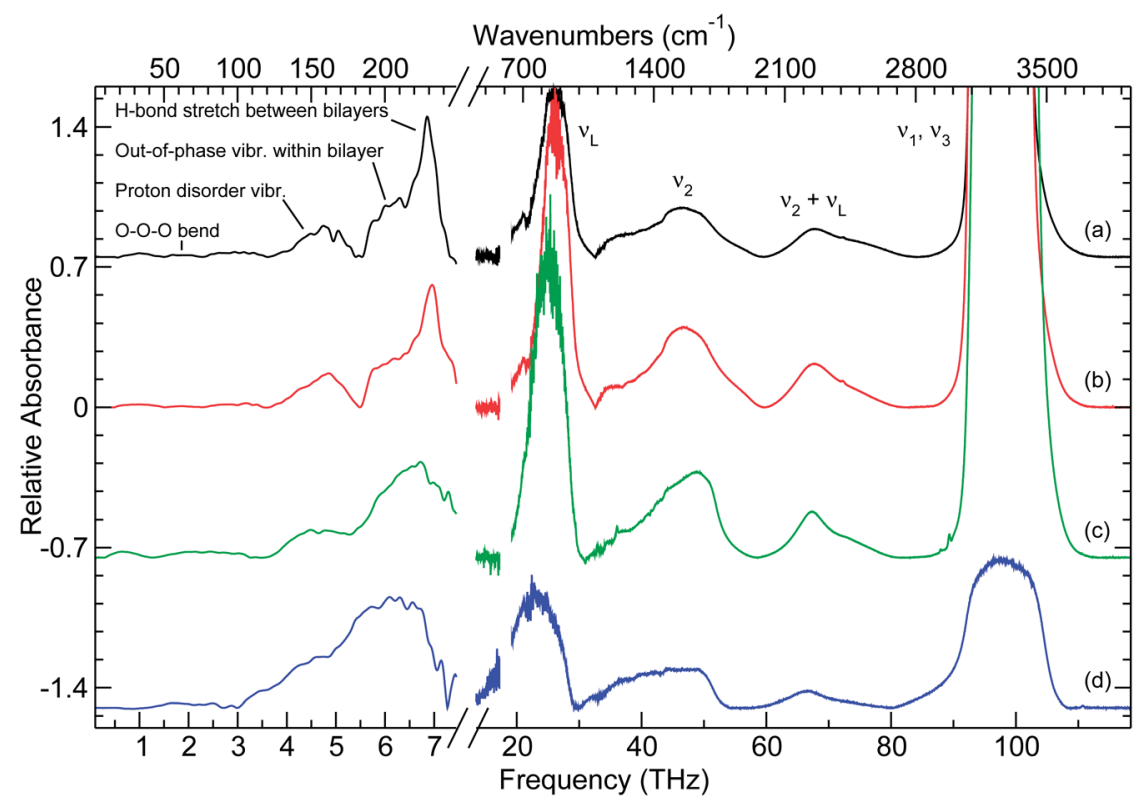

Fig. 5 Spectra of water ice deposited at different temperatures: (a) 175 K; (b) 140 K; (c) $125 \mathrm{~K}$; and (d) $10 \mathrm{~K}$. The figure shows the complete spectral window covered by the setup as used in this work. 
work. Fig. 6 shows the THz spectra of crystalline ices at $100 \mathrm{~K}$ (black curves), $75 \mathrm{~K}$ (red curves), and $10 \mathrm{~K}$ (green curves), with the exception of one spectrum of water ice that is at $140 \mathrm{~K}$ (black curve) instead of $100 \mathrm{~K}$. The deposition temperatures for all the species are the same as described in Fig. 3. Apart from the acids, which behave differently, all the other species have strong changes that are dependent on the temperature variations of the ice. At $100 \mathrm{~K}$, several sharp peaks are visible for water, methanol, acetaldehyde, and acetone. These peaks become sharper at $75 \mathrm{~K}$ and clearly stronger at $10 \mathrm{~K}$. At low temperatures, new peaks are detected. Moreover, these peaks reveal a temperature dependent blueshift at lower temperatures. The peak positions at all the temperatures investigated are summarized in Table 2.

As discussed before, these transformations are reversible. The peak shifting and broadening in the $\mathrm{THz}$ spectra results from the anharmonicity of the vibrational potential, and thus provide a spectral fingerprint of the intermolecular forces. Since the anharmonicity of the Morse potential decreases the spacing

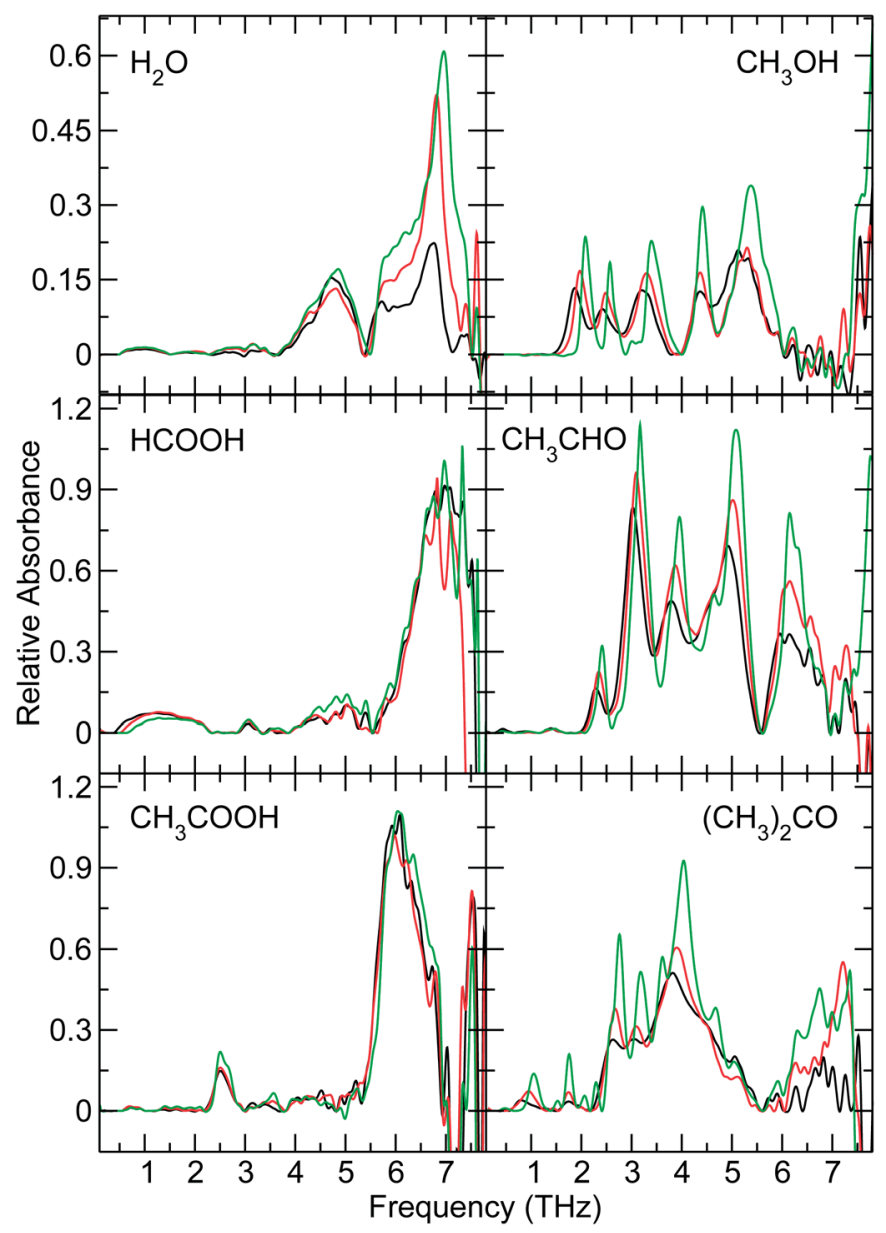

Fig. 6 THz spectra of crystalline ices at different temperatures: (black curves) $100 \mathrm{~K}$; (red curves) $75 \mathrm{~K}$; and (green curves) $10 \mathrm{~K}$. The black curve of water ice is acquired at $140 \mathrm{~K}$. 
between adjacent vibrational levels, hot bands exhibit redshifts, i.e., appear at lower frequencies than the corresponding fundamental transitions. The vibrationally averaged structure of the crystal is then temperature dependent since the wavefunctions of the hot bands are different from each other and the ground state. At low temperature, only the lower lying states on the vibrational potential are populated and the absorption bands appear blueshifted and sharper with respect to the absorption bands due to hot bands.

Table 2 List of absorption bands of the molecules studied at different temperatures in the $\mathrm{THz}$ spectral region between 0.3 and $7.5 \mathrm{THz}$

\begin{tabular}{|c|c|c|c|c|c|c|c|}
\hline \multicolumn{3}{|l|}{$\mathrm{c}-\mathrm{H}_{2} \mathrm{O}$} & \multirow{2}{*}{$\frac{a-H_{2} \mathrm{O}}{10 \mathrm{~K}}$} & \multicolumn{3}{|l|}{$\mathrm{c}-\mathrm{CH}_{3} \mathrm{OH}$} & \multirow{2}{*}{$\begin{array}{l}\mathrm{a}-\mathrm{CH}_{3} \mathrm{OH} \\
10 \mathrm{~K}\end{array}$} \\
\hline $140 \mathrm{~K}$ & $75 \mathrm{~K}$ & $10 \mathrm{~K}$ & & $100 \mathrm{~K}$ & $75 \mathrm{~K}$ & $10 \mathrm{~K}$ & \\
\hline $1.0 \mathrm{w}$ & $1.0 \mathrm{w}$ & $1.0 \mathrm{w}$ & & & & & $1.0 \mathrm{w}$ \\
\hline $1.9 \mathrm{vw}$ & $1.9 \mathrm{vw}$ & $1.9 \mathrm{vw}$ & $1.7 \mathrm{w}$ & $1.85 \mathrm{~s}$ & $1.95 \mathrm{~s}$ & $2.1 \mathrm{~s}$ & $1.9 \mathrm{w}$ \\
\hline $2.7 \mathrm{vw}$ & $2.7 \mathrm{vw}$ & $2.7 \mathrm{vw}$ & & $2.4 \mathrm{~s}$ & $2.5 \mathrm{~s}$ & $2.6 \mathrm{~s}$ & $2.3 \mathrm{w}$ \\
\hline $3.1 \mathrm{w}$ & $3.1 \mathrm{w}$ & $3.1 \mathrm{w}$ & $3.5 \mathrm{~m}$ & & & $3.0 \mathrm{w}$ & \\
\hline $4.3 \mathrm{~m}$ & $4.3 \mathrm{~m}$ & $4.3 \mathrm{~m}$ & & $3.2 \mathrm{~s}$ & $3.3 \mathrm{~s}$ & $3.4 \mathrm{~s}$ & $3.5 \mathrm{~m}$ \\
\hline $4.7 \mathrm{~s}$ & $4.8 \mathrm{~s}$ & $4.9 \mathrm{~s}$ & $4.6 \mathrm{~s}, \mathrm{sh}, \mathrm{br}$ & $4.37 \mathrm{~s}$ & $4.37 \mathrm{~s}$ & 4.43 vs & $4.4 \mathrm{~s}, \mathrm{br}$ \\
\hline $\begin{array}{l}5.7 \mathrm{~m}, \mathrm{sh} \\
6.7 \mathrm{~s}\end{array}$ & $\begin{array}{l}5.7 \mathrm{~s}, \mathrm{sh} \\
6.8 \mathrm{vs}\end{array}$ & $\begin{array}{l}5.7 \mathrm{~s}, \mathrm{sh} \\
6.9 \mathrm{vs}\end{array}$ & $6.2 \mathrm{vs}, \mathrm{br}$ & $5.1 \mathrm{~s}$ & $5.3 \mathrm{~s}$ & 5.4 vs & $6.8 \mathrm{~s}$ \\
\hline \multicolumn{2}{|l|}{$\mathrm{c}-\mathrm{HCOOH}$} & & $\mathrm{a}-\mathrm{HCOOH}$ & \multicolumn{2}{|l|}{$\mathrm{c}-\mathrm{CH}_{3} \mathrm{CHO}$} & & a- $\mathrm{CH}_{3} \mathrm{CHO}$ \\
\hline $100 \mathrm{~K}$ & $75 \mathrm{~K}$ & $10 \mathrm{~K}$ & $10 \mathrm{~K}$ & $100 \mathrm{~K}$ & $75 \mathrm{~K}$ & $10 \mathrm{~K}$ & $10 \mathrm{~K}$ \\
\hline $1.2 \mathrm{w}$ & $1.4 \mathrm{w}$ & $1.6 \mathrm{w}$ & & $0.4 \mathrm{vw}$ & $0.4 \mathrm{vw}$ & $0.4 \mathrm{vw}$ & \\
\hline $3.0 \mathrm{w}$ & $3.0 \mathrm{w}$ & $3.0 \mathrm{w}$ & & $0.9 \mathrm{vw}$ & $0.9 \mathrm{vw}$ & $0.9 \mathrm{vw}$ & \\
\hline $3.6 \mathrm{vw}$ & $3.6 \mathrm{vw}$ & $3.6 \mathrm{vw}$ & & $1.4 \mathrm{vw}$ & $1.4 \mathrm{vw}$ & $1.4 \mathrm{vw}$ & \\
\hline $4.8 \mathrm{w}$ & $4.8 \mathrm{w}$ & $4.8 \mathrm{~m}$ & $4.3 \mathrm{vw}$ & $2.28 \mathrm{~m}$ & $2.36 \mathrm{~m}$ & $2.43 \mathrm{~m}$ & \\
\hline \multirow[t]{5}{*}{$7.0 \mathrm{vs}$} & $7.0 \mathrm{vs}$ & $7.0 \mathrm{vs}$ & $6.8 \mathrm{vs}, \mathrm{br}$ & $3.0 \mathrm{~s}$ & $3.1 \mathrm{vs}$ & 3.19 vs & \\
\hline & & & & $3.8 \mathrm{~m} \mathrm{~s}^{-1}$ & $3.88 \mathrm{~s}$ & $\begin{array}{l}3.96 \mathrm{~s} \\
4.6 \mathrm{w}, \mathrm{sh}\end{array}$ & $3.5 \mathrm{~s}, \mathrm{br}$ \\
\hline & & & & $4.9 \mathrm{~s}$ & $5.0 \mathrm{~s}$ & $5.1 \mathrm{vs}$ & \\
\hline & & & & $6.0 \mathrm{~m} \mathrm{~s}^{-1}$ & $6.1 \mathrm{~s}$ & $6.2 \mathrm{~s}$ & $6.0 \mathrm{~m}, \mathrm{br}$ \\
\hline & & & & $7.3 \mathrm{~m}$ & $7.3 \mathrm{~m}$ & $7.3 \mathrm{~m}$ & \\
\hline \multicolumn{2}{|c|}{$\mathrm{c}-\mathrm{CH}_{3} \mathrm{COOH}$} & & $\mathrm{a}-\mathrm{CH}_{3} \mathrm{COOH}$ & \multicolumn{2}{|c|}{$\mathrm{c}-\left(\mathrm{CH}_{3}\right)_{2} \mathrm{CO}$} & & $\mathrm{a}-\left(\mathrm{CH}_{3}\right)_{2} \mathrm{CO}$ \\
\hline $100 \mathrm{~K}$ & $75 \mathrm{~K}$ & $10 \mathrm{~K}$ & $10 \mathrm{~K}$ & $100 \mathrm{~K}$ & $75 \mathrm{~K}$ & $10 \mathrm{~K}$ & $10 \mathrm{~K}$ \\
\hline $0.8 \mathrm{vw}$ & $0.8 \mathrm{vw}$ & $0.8 \mathrm{vw}$ & & $0.48 \mathrm{vw}$ & $0.48 \mathrm{vw}$ & $0.48 \mathrm{vw}$ & \\
\hline $1.8 \mathrm{vw}$ & $1.8 \mathrm{vw}$ & $1.8 \mathrm{vw}$ & & $0.8 \mathrm{vw}$ & $0.96 \mathrm{vw}$ & $1.05 \mathrm{w}$ & \\
\hline $2.5 \mathrm{~m}$ & $2.5 \mathrm{~m}$ & $2.5 \mathrm{~m}$ & & $1.3 \mathrm{vw}$ & $1.45 \mathrm{vw}$ & $1.53 \mathrm{vw}$ & \\
\hline $3.4 \mathrm{w}$ & $3.5 \mathrm{w}$ & $3.6 \mathrm{w}$ & $3.4 \mathrm{~m}$ & $1.75 \mathrm{vw}$ & $1.75 \mathrm{vw}$ & $1.75 \mathrm{w}$ & \\
\hline $4.3 \mathrm{w}$ & $4.3 \mathrm{w}$ & $4.3 \mathrm{w}$ & $4.3 \mathrm{w}$ & $2.0 \mathrm{vw}$ & $2.02 \mathrm{vw}$ & $2.06 \mathrm{vw}$ & \\
\hline $5.2 \mathrm{w}$ & $5.2 \mathrm{w}$ & $5.2 \mathrm{w}$ & & & & $2.3 \mathrm{w}$ & \\
\hline \multirow[t]{11}{*}{$5.9 \mathrm{vs}$} & $6.0 \mathrm{vs}$ & $6.1 \mathrm{vs}$ & $6.2 \mathrm{vs}, \mathrm{br}$ & & & $2.57 \mathrm{vw}, \mathrm{sh}$ & \\
\hline & & & & $2.63 \mathrm{~m}$ & $2.68 \mathrm{~m}$ & $2.76 \mathrm{~s}$ & \\
\hline & & & & $3.04 \mathrm{~m}$ & $3.1 \mathrm{~m}$ & $3.18 \mathrm{~s}$ & \\
\hline & & & & & & $3.61 \mathrm{~m}, \mathrm{sh}$ & $3.5 \mathrm{vs}, \mathrm{br}$ \\
\hline & & & & $3.8 \mathrm{~s}$ & $3.9 \mathrm{~s}$ & 4.04 vs & \\
\hline & & & & $4.5 \mathrm{vw}, \mathrm{sh}$ & $4.5 \mathrm{vw}, \mathrm{sh}$ & $4.7 \mathrm{~m}, \mathrm{sh}$ & \\
\hline & & & & $5.05 \mathrm{w}, \mathrm{sh}$ & $5.05 \mathrm{w}, \mathrm{sh}$ & $5.05 \mathrm{w}, \mathrm{sh}$ & $5.0 \mathrm{w}, \mathrm{sh}$ \\
\hline & & & & $5.6 \mathrm{w}$ & $5.6 \mathrm{w}$ & $5.6 \mathrm{w}$ & \\
\hline & & & & $5.8 \mathrm{w}$ & $5.8 \mathrm{w}$ & $5.9 \mathrm{w}$ & $5.8 \mathrm{w}$ \\
\hline & & & & $6.3 \mathrm{w}$ & $6.3 \mathrm{w}$ & $6.3 \mathrm{~m}$ & $6.3 \mathrm{w}$ \\
\hline & & & & $6.8 \mathrm{w}$ & $6.8 \mathrm{w}$ & $6.8 \mathrm{~m} \mathrm{~s}^{-1}$ & $7.0 \mathrm{~s}$ \\
\hline
\end{tabular}

${ }^{a} \mathrm{vw}=$ very weak, $\mathrm{w}=$ weak, $\mathrm{m}=$ medium, $\mathrm{s}=$ strong, $\mathrm{vs}=$ very strong, $\mathrm{sh}=$ shoulder, $\mathrm{br}=$ broad. 
Moreover, it is possible for features not present at high temperatures to grow in at lower temperatures. If the shape of the vibrational potential is such that there are multiple local minima, corresponding to different crystal structures, at higher temperatures, different vibrational states corresponding to these different structures are populated. Based on the different processing of the ice, it is possible to freeze-out the different structures and thus have one feature split into several at lower temperature. Thus, $\mathrm{THz}$ spectra of crystalline ices have the potential to give direct information on the temperature of the studied system.

$\mathrm{THz}$ spectroscopy is not only sensitive to intermolecular forces, it also probes low energy intramolecular modes such as torsional motions of individual molecules. Some torsion-vibration spectra of methanol, acetaldehyde, acetic acid, and acetone are already available in the literature as reviewed by Shimanouchi. ${ }^{\mathbf{4 0}}$ These data are in good agreement with our $\mathrm{THz}$ laboratory spectra: methanol has a torsional mode at $6 \mathrm{THz}$ that corresponds to the very strong mode at $5.4 \mathrm{THz}$ of our spectrum of crystalline methanol at $10 \mathrm{~K}$ as shown in Table 2; the $4.6 \mathrm{THz}$ mode of crystalline acetaldehyde found in our spectrum at $10 \mathrm{~K}$ corresponds to the torsional mode assigned at $4.5 \mathrm{THz}$; acetic acid has a torsional mode at 2.8 $\mathrm{THz}$ that matches well with a band at $2.5 \mathrm{THz}$ as seen in our crystalline spectrum at $10 \mathrm{~K}$; the acetone torsional mode at $3.2 \mathrm{THz}$ overlaps with a strong band at 3.18 $\mathrm{THz}$ as found in our spectrum of crystalline acetone at $10 \mathrm{~K}$.

\subsection{The temperature effect: amorphous ices}

As previously discussed, amorphous ice goes through irreversible transformations if annealed to higher temperatures. Fig. 7 shows the THz spectra of amorphous ices as deposited at $10 \mathrm{~K}$ (black curves) and heated to higher temperatures. In the left-panel of Fig. 7, amorphous water ice is heated to $125 \mathrm{~K}$ (red curve) and $150 \mathrm{~K}$ (green curve). Comparing these spectra to those acquired at the same temperatures and shown in Fig. 5 gives information on the degree of crystallinity of the ice. The red and green curves in Fig. 5 represent ices directly deposited at 140 and $125 \mathrm{~K}$, respectively. These ices clearly present the highest degree of crystallization at the selected temperatures, whereas amorphous ices heated to the same temperatures show an amorphous component underneath the crystalline line-shapes. This indicates that the ice is partially reorganized but still largely amorphous. The degree of crystallinity increases with temperature as expected. This is also the case for methanol and acetone. Amorphous methanol is heated to $75 \mathrm{~K}$ (red curve), and annealed to $140 \mathrm{~K}$ for $\sim 10 \mathrm{~min}$ and cooled to $100 \mathrm{~K}$ (green curve). Spectra at 10 and $75 \mathrm{~K}$ do not present major differences indicating that the ice is still amorphous. After annealing, the ice shows a clear crystalline structure. The features are however broader than the ones shown in Fig. 6, indicating that the crystallization process is not yet completed. Amorphous acetone heated to $75 \mathrm{~K}$ (red curve), $100 \mathrm{~K}$ (green curve), and annealed to $150 \mathrm{~K}$ and cooled to $100 \mathrm{~K}$ (blue curve), shows an even clearer amorphous component even when the ice is annealed for $\sim 10 \mathrm{~min}$.

Amorphous acetaldehyde approaches a fully crystalline structure at lower temperatures than the other species studied here. In the right-center panel of Fig. 7, amorphous acetaldehyde is heated to $40 \mathrm{~K}$ (red curve), $60 \mathrm{~K}$ (green curve), $80 \mathrm{~K}$ (blue curve), and annealed to $125 \mathrm{~K}$ for $\sim 5 \mathrm{~min}$ and cooled back to $10 \mathrm{~K}$ (brown curve). Acetaldehyde goes through crystallization at temperatures above 


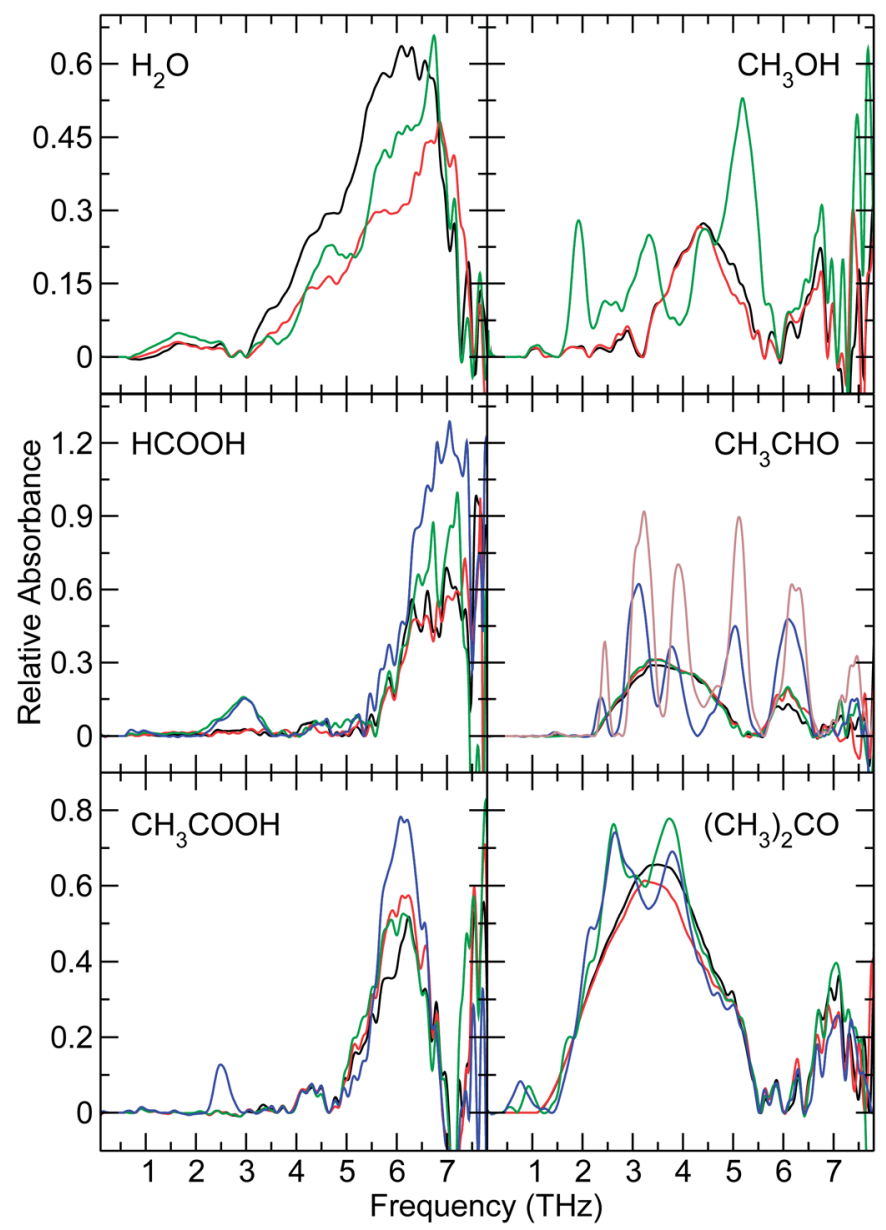

Fig. 7 THz spectra of amorphous ices at different temperatures: see text for the assignment of the different temperatures.

$70 \mathrm{~K}$ under our experimental conditions, and at $80 \mathrm{~K}$ shows already an almost perfect crystalline structure comparable to the one shown in Fig. 6. The annealing process does not greatly change the degree of crystallinity. The difference here is the temperature of acquisition of the spectra (i.e., $80 \mathrm{~K}$ vs. $10 \mathrm{~K}$ ). As shown in Fig. 6, crystalline acetaldehyde ice shows blueshifted, sharper, and more intense features at low temperatures. This is also the case for the spectra in Fig. 7.

Amorphous formic acid is heated to $75 \mathrm{~K}$ (red curve), annealed to $150 \mathrm{~K}$ for $\sim 10$ min and cooled back to $75 \mathrm{~K}$ (green curve), and cooled to $10 \mathrm{~K}$ (blue curve). The acid presents small changes in the band profile of the strongest feature at $\sim 6.8$ $\mathrm{THz}$ when the ice temperature is increased. However, after the ice is annealed to $150 \mathrm{~K}$ for $\sim 10$ minutes a new feature appears at $3 \mathrm{THz}$. Cooling the now crystalline ice to $10 \mathrm{~K}$ allows for an increase of the intensity of the main feature at $6.8 \mathrm{THz}$. This is consistent with the behavior of the other crystalline ices as previously discussed, but is not consistent with the almost complete lack of changes seen in crystalline formic acid as shown in Fig. 6. It is interesting to note that the new 
crystalline band at $3 \mathrm{THz}$ does not change with changes in temperature, while only the main band increases in intensity at lower temperatures. However the band profile of the main band at $10 \mathrm{~K}$ is now similar to the one of the crystalline ice as shown in Fig. 6 indicating that the ice is fully crystalline. Further experiments are needed to show whether the crystalline band at $6.8 \mathrm{THz}$ is temperature dependent as shown in Fig. 7 or is temperature independent (see Fig. 6). A possible explanation is that the ice was not fully crystalline when the second spectrum at $75 \mathrm{~K}$ was acquired. Since the acquisition of a $\mathrm{THz}$ spectrum lasts for $\sim 2 \mathrm{~h}$ with our current setup, the ice may have had enough time to reorganize at this temperature and the spectrum at $10 \mathrm{~K}$ shows that more than a temperature dependence.

A similar effect is seen in the acetic acid spectra. Amorphous acetic acid is heated to $75 \mathrm{~K}$ (red curve), $100 \mathrm{~K}$ (green curve), and annealed to $200 \mathrm{~K}$ for $\sim 5 \mathrm{~min}$ before being cooled back to $100 \mathrm{~K}$ (blue curve). Also for acetic acid, a new band at 2.5 THz is present in the annealed spectrum and the main band at $6.2 \mathrm{THz}$ looks sharper and more intense. The fact that this band looks sharper already at $100 \mathrm{~K}$ is an indication that the ice is fully crystalline, adding support to our idea that the changes of the main band profile at $6.8 \mathrm{THz}$ in formic acid are due to further crystallization more than to the energy state distribution of the fundamental and hot band features whose intensities are a strong function of temperature.

In an attempt to provide molecular insight into why the structures of the amorphous and crystalline acid ices present similar $\mathrm{THz}$ spectra, ab initio quantum chemistry calculations were performed on a dimer of each species. The cyclic dimer structure is such that the acidic proton of one molecule is donating to the carbonyl group of the second molecule and vice-versa. While these are gasphase dimers, they can provide some insight into solid-phase structures as well. The hydrogen-bonded interaction that forms a dimer is indeed quite strong and dimers can therefore dominate the structure of pure ices. Our calculations provide evidence in support of this. In the case of the formic acid dimer, the calculations reveal a strong mode corresponding to a rocking of the two molecules, which stretches their hydrogen bonds, at $235 \mathrm{~cm}^{-1}(7.0 \mathrm{THz})$. This is in good agreement with the formic acid mode observed in the experimental spectrum at $\sim 7 \mathrm{THz}$. A similar mode is found in the calculated vibrations for the acetic acid dimer at $160 \mathrm{~cm}^{-1}(4.8 \mathrm{THz})$. According to our experimental data, however, the strongest mode of acetic acid peaks at $\sim 6 \mathrm{THz}$. Differences between MP2 simulations and THz laboratory results can be explained by the more constrained nature of the molecules in the ice that can cause the frequency of this rocking vibration to be higher in energy in the solid phase than in the gas phase. Overall, while the predicted mode of acetic acid does not agree perfectly with the experimentally-measured transition, the calculations produce the same red shift in frequency, relative to the formic acid mode, as observed in the experiments. This offers evidence to support our assignments of these transitions, since a model of harmonic vibrations predicts a decrease in frequency when mass is increased, as is the case when a heavier functional group is added $\left(-\mathrm{CH}_{3}\right.$ vs. H). Therefore, similarities between $\mathrm{THz}$ spectra of amorphous and crystalline acidic ices can be explained by the direct deposition of acidic dimers onto the substrate. As a result of the strong hydrogen-bonding interaction between dimers, the features around 6 and $7 \mathrm{THz}$ remain largely unchanged when amorphous ices are annealed. 


\subsection{The composition effect: binary mixtures}

Although there are some far-IR spectra of mixed binary and more complex ices reported in the literature, there are no data available at low frequencies (between 0.3 and $3 \mathrm{THz}$ ). For instance, Moore and Hudson ${ }^{18}$ mixed water with other astrophysically-relevant species with a ratio of $10: 1$ and $2: 1$. All their amorphous ices were deposited at $13 \mathrm{~K}$, while the crystalline mixtures were obtained by annealing amorphous ices to $155 \mathrm{~K}$ and cooling it back to $13 \mathrm{~K}$. This procedure may lead to some desorption, diffusion, and reorganization. However, we showed that annealed ices are hardly fully crystalline unless the ice is annealed to temperatures close to their desorption temperature for several minutes. This can also cause desorption of part of the ice. Allodi et al. ${ }^{16}$ showed that $\mathrm{CO}_{2}$ mixed in water ice segregates at higher temperatures between the bilayers of water ice, disrupting the crystalline structure of water ice. Spectra of these mixtures are hard to interpret if not supported by proper $\mathrm{THz}$ ice-database that includes spectra of pure ices at different temperatures and different mixtures deposited at high temperatures. Therefore, our goal here is the investigation of the spectral changes of crystalline ice when binary mixtures are deposited at different ratios and at high temperatures.

The top panels of Fig. 8 show the spectra of water and methanol mixed ices with a ratio of $2: 1,1: 1$, and $0.5: 1$ deposited at $140 \mathrm{~K}$. By looking at both the THz and the mid-IR regions, it is possible to conclude that although the ices are deposited at the same temperature and under the same experimental conditions, the composition of the ice has a strong effect on the spectral profile. It should be noted that the mid-IR spectra shown in the figure are acquired during deposition to have non-saturated infrared bands (64 co-added scans). This allows us to monitor the profile of the fundamental vibrational modes of water and methanol in the mid-IR and retrieve information from both the THz and the mid-IR regions.

The $2: 1$ mixture (Fig. 8a) shows the clear signs of crystalline water ice with some impurities due to the presence of methanol. As opposed to the case of $\mathrm{CO}_{2}$ that has been shown to affect strongly the water modes in the THz, methanol does not seem to have a strong impact on the $\mathrm{H}$-bond stretch mode between bilayers or the proton disorder mode of water ice. ${ }^{16}$ When the amount of methanol is comparable to the amount of water (1:1 mixture, Fig. $8 \mathrm{~b})$, however, the aforementioned water modes are affected by the methanol and a single broad band appears at $\sim 6 \mathrm{THz}$. Three water modes and two methanol modes lay on the region covered by this broad band. The last mixture (0.5:1, Fig. 8c) shows four peaks that partially overlap with each other and most likely are due to the single peaks seen in the spectra of pure crystalline water and methanol ices. However, they are slightly shifted. This indicates that water affects the structure of methanol more than the other way around and that the interaction of the two molecules with each other can be investigated in the THz.

The bottom panels of Fig. 8 shows the spectra of water and acetaldehyde mixed ices with a ratio of $2: 1,1: 1$, and $0.5: 1$ deposited at $125 \mathrm{~K}$. In this case, water is not yet crystalline, but our $\mathrm{THz}$ spectra show that the degree of reorganization of the ice is substantially higher than for amorphous water ice at $10 \mathrm{~K}$. By comparing the three mixtures we can conclude that the water structure is affected by the presence of acetaldehyde in a way that is not strongly dependent on the amount of acetaldehyde in the ice: two broad and strong peaks due to water ice are visible in 


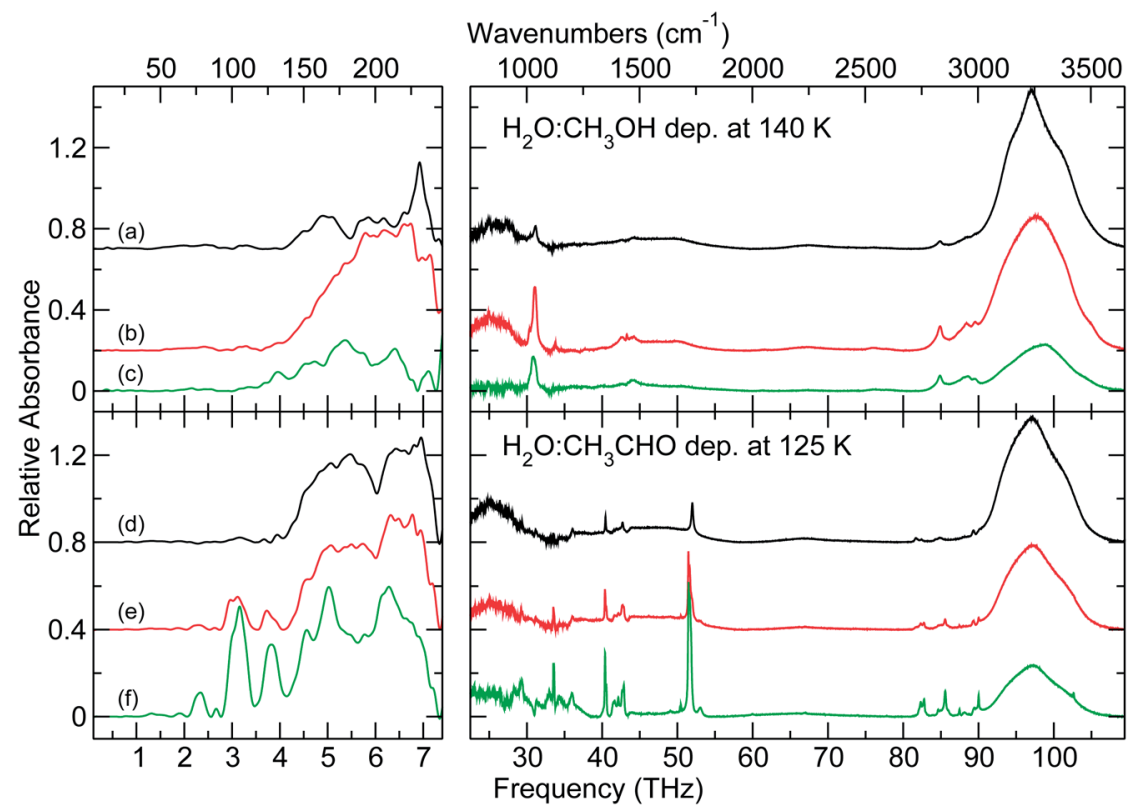

Fig. $8 \mathrm{THz}$ spectra of crystalline mixed ices at $10 \mathrm{~K}$. The left panels show $\mathrm{THz}$ spectra of $\mathrm{H}_{2} \mathrm{O}: \mathrm{CH}_{3} \mathrm{OH} 2: 1$ (a), $1: 1$ (b), and $0.5: 1$ (c) mixtures (top) and $\mathrm{H}_{2} \mathrm{O}: \mathrm{CH}_{3} \mathrm{CHO} 2: 1$ (d), $1: 1$ (e), and $0.5: 1$ (f) mixtures (bottom). The right panels show the same ices in the mid-IR. In this case, mid-IR spectra are acquired during deposition to obtain non-saturated features.

all the investigated mixtures and their profile does not change in the different mixtures. Another important conclusion is that peaks due to crystalline acetaldehyde grow in proportionally with the amount of acetaldehyde in the mixture and are visible even when acetaldehyde is half of the total amount of water in the ice. These two conclusions indicate that acetaldehyde and water are not extensively mixed at $125 \mathrm{~K}$ and that the crystalline structure of acetaldehyde is preserved. It is possible that acetaldehyde is segregating and crystallizing in the pores of water ice that are still present at $125 \mathrm{~K}$.

\section{Astrophysical implications}

All the species studied in this work are astrochemically-relevant and have been identified in the ISM: water was first detected in 1969 in Sgr B2, Orion, and W49; ${ }^{\mathbf{4 1}}$ carbon monoxide was detected in 1970 in Orion; ${ }^{42}$ methanol was first detected in 1970 in Sgr B2;3 formic acid was detected in 1971 in Sgr B2;4 acetaldehyde was detected in 1973 in Sgr B2; ${ }^{45,46}$ acetic acid was first detected in 1997 in Sgr B2; ${ }^{47}$ and acetone was detected in 1987 in Sgr B2. ${ }^{48}$

The astrochemical origin of the species studied here is only well understood in some cases. For instance, CO forms efficiently in the gas phase; water has been proven to be formed efficiently at cold temperatures in the solid phase through surface reactions (for a review see van Dishoeck et al. ${ }^{49}$ ); the surface hydrogenation of $\mathrm{CO}$ ice leads to the formation of formaldehyde and methanol at low 
temperatures; ${ }^{31,50}$ formic acid is formed through the surface hydrogenation of the HOCO complex. ${ }^{51}$ However, little is known about the formation of other species such as acetaldehyde, acetic acid, and acetone. Although non-energetic surface reaction pathways leading to the formation of the more complex species studied in this work have not yet been investigated in the laboratory, several models indicate that those species should be formed in the solid phase and could participate in the formation of even more complex species. ${ }^{11}$ For instance, Bisschop et al. ${ }^{52}$ studied the surface hydrogenation of acetaldehyde and found that it converts to ethanol $\left(\mathrm{C}_{2} \mathrm{H}_{5} \mathrm{OH}\right)$ or to $\mathrm{CH}_{4}, \mathrm{H}_{2} \mathrm{CO}$, and $\mathrm{CH}_{3} \mathrm{OH}$.

Interstellar ices are mainly composed of water, carbon monoxide, carbon dioxide, methane, ammonia, methanol, and formaldehyde. The spectroscopic identification of other less abundant species, such as formic acid and acetaldehyde studied here, relies on weak bands in the mid-IR that do not overlap with the stronger bands of the main ice components. The $\mathrm{OH}$ and $\mathrm{CH}$ bending modes of $\mathrm{HCOOH}$ at $7.25 \mu \mathrm{m}$ and the $\mathrm{CH}_{3}$ deformation of $\mathrm{CH}_{3} \mathrm{CHO}$ at $7.41 \mu \mathrm{m}$ are good examples. Solid-state abundances of formic acid are between 1 and $5 \%$ in both low and high mass star forming regions with respect to $\mathrm{H}_{2} \mathrm{O} .{ }^{53-56}$ The detection of acetaldehyde is less certain, but abundances comparable with those of formic acid have been reported. ${ }^{55,56}$

This work shows that $\mathrm{THz}$ features from molecules such as formic acid, acetaldehyde, acetic acid, and acetone are distinct and retain important information on the composition and structure of the ice. Therefore, a spectral investigation of these species in the $\mathrm{THz}$ range in space has the potential to contribute to the identification of the composition of interstellar ices. This can be used to better understand: ( $i$ ) the spatial distribution of such species in the ISM since THz spectra can be acquired ideally along any line of sight; (ii) the chemistry that governs the formation of such species, since $\mathrm{THz}$ features are a unique fingerprint of the chemical composition of the ice; (iii) and the physical conditions that the ice experiences during the evolution of star-forming regions, since $\mathrm{THz}$ modes are sensitive to the structure of the ice.

\section{Conclusions}

We present the first THz results $\left(0.3-7.5 \mathrm{THz} ; 10-250 \mathrm{~cm}^{-1}\right)$ from astrophysicallyrelevant species that share the same functional groups, such as formic acid and acetic acid, and acetaldehyde and acetone, compared to more abundant interstellar molecules like water, CO, and methanol. Some pure and mixed binary ices are also discussed here. The effect of the composition and the structure of the ice at different temperature is shown. Below we enumerate our conclusions:

1. Our spectra of pure water, $\mathrm{CO}$, and methanol ices at different temperatures agree with previous literature studies. Since our spectral coverage extends to a range previously uninvestigated $(0.3-3 \mathrm{THz})$, we were able to identify several new features in the methanol spectrum as we did for water ice in a previous study. ${ }^{16}$

2. $\mathrm{THz}$ spectra of crystalline formic acid and acetic acid deposited at high temperatures present a strong broad feature around $7 \mathrm{THz}$ and are quite flat elsewhere. THz spectra of crystalline methanol, acetaldehyde, and acetone have a forest of sharp, often strong features. In general, the THz spectrum of an individual molecule depends on the functional groups present in the molecule. 
3. THz spectra of amorphous species that share the same functional group are similar. Methanol, acetaldehyde, and acetone have a broad feature around $4 \mathrm{THz}$, while formic acid and acetic acid have a broad feature around $7 \mathrm{THz}$.

4. Ab initio quantum chemical calculations on dimers of formic acid and acetic acid suggest the assignment of the strong band observed at $\sim 7 \mathrm{THz}$ to a rocking mode of two molecules. The similarities between THz spectra of amorphous and crystalline acidic ices can then be explained by the direct deposition of dimers from the gas phase and the strong hydrogen-bonding interaction between dimers.

5. Crystalline ices undergo reversible transformations when the ice is heated or cooled to different temperatures. Amorphous ices undergo irreversible transformations when the ice is heated. THz spectra are sensitive to both reversible and irreversible changes within the structure of the ice.

6. $\mathrm{THz}$ spectra retain information of the composition of the ice, as can be seen in our studies of binary mixtures. This is shown when binary mixtures are studied. This information can be used to understand dynamics within the ice such as diffusion, reaction, and desorption.

7. Our work demonstrates the importance of THz spectroscopy in the study of astrochemical ices and contributes to the body of experimental laboratory data needed to interpret astronomical observations from Herschel Space Observatory, SOFIA, and ALMA.

\section{Acknowledgements}

This work was supported by the NSF CRIF:ID and CSDM programs and the NASA Exobiology and Laboratory Astrophysics programs. The authors thank Coherent, Inc. for the loan of the Optical Parametric Amplifier used in these experiments. S.I. acknowledges support from a Niels Stensen Fellowship and a Marie Curie Fellowship (FP7-PEOPLE-2011-IOF-300957). B.A.M. gratefully acknowlwdges funding by an NSF Graduate Research Fellowship. M.A.A. was supported by the Department of Defense (DoD) Air Force Office of Scientific Research, National Defense Science and Engineering Graduate (NDSEG) Fellowship, 32 CFR 168a.

\section{References}

1 J. E. Elsila, D. P. Glavin and J. P. Dworkin, Meteorit. Planet. Sci., 2009, 44, 13231330.

2 E. Congiu, G. Fedoseev, S. Ioppolo, F. Dulieu, H. Chaabouni, S. Baouche, J. L. Lemaire, C. Laffon, P. Parent, T. Lamberts, H. M. Cuppen and H. Linnartz, Astrophys. J., 2012, 750, L12.

3 E. Congiu, H. Chaabouni, C. Laffon, P. Parent, S. Baouche and F. Dulieu, J. Chem. Phys., 2012, 137, 054713.

4 G. Fedoseev, S. Ioppolo, T. Lamberts, J. F. Zhen, H. M. Cuppen and H. Linnartz, J. Chem. Phys., 2012, 137, 054714.

5 M. Minissale, G. Fedoseev, E. Congiu, S. Ioppolo, F. Dulieu and H. Linnartz, Phys. Chem. Chem. Phys., 2014, 16, 8257.

6 S. Ioppolo, G. Fedoseev, M. Minissale, E. Congiu, F. Dulieu and H. Linnartz, Phys. Chem. Chem. Phys., 2014, 16, 8270.

7 R. L. Pulliam, B. A. McGuire and A. J. Remijan, Astrophys. J., 2012, 751, 1. 
8 A. Nummelin, P. Bergman, Å. Hjalmarson, P. Friberg, W. M. Irvine, T. J. Millar, M. Ohishi and S. Saito, Astrophys. J. Suppl., 2000, 128, 213-243.

9 A. Horn, H. Møllendal, O. Sekiguchi, E. Uggerud, H. Roberts, E. Herbst, A. A. Viggiano and T. D. Fridgen, Astrophys. J., 2004, 611, 605-614.

10 R. T. Garrod, S. L. W. Weaver and E. Herbst, Astrophys. J., 2008, 682, 283-302.

11 R. T. Garrod, Astrophys. J., 2013, 765, 60.

12 K. I. Öberg, S. Bottinelli and E. F. van Dishoeck, Astron. Astrophys., 2009, 494, L13-L16.

13 J. C. Laas, R. T. Garrod, E. Herbst and S. L. Widicus Weaver, Astrophys. J., 2011, 728, 71.

14 J. C. Laas, B. M. Hays and S. L. Widicus Weaver, J. Phys. Chem. A, 2013, 117, 9548-9554.

15 K. I. Öberg, A. C. A. Boogert, K. M. Pontoppidan, S. van den Broek, E. F. van Dishoeck, S. Bottinelli, G. A. Blake and N. J. Evans, II, Astrophys. J., 2011, 740, 109.

16 M. A. Allodi, S. Ioppolo, M. J. Kelley, B. A. McGuire and G. A. Blake, Phys. Chem. Chem. Phys., 2014, 16, 3442-3455.

17 J. E. Bertie, Appl. Spectrosc., 1968, 22, 634-640.

18 M. H. Moore and R. L. Hudson, Astron. Astrophys. Suppl. Ser., 1994, 103, 45-56.

19 M. Clerici, M. Peccianti, B. E. Schmidt, L. Caspani, M. Shalaby, M. Giguère, A. Lotti, A. Couairon, F. Légaré, T. Ozaki, D. Faccio and R. Morandotti, Phys. Rev. Lett., 2013, 110, 253901.

20 P. R. Griffiths and J. A. de Haseth, Fourier Transform Infrared Spectroscopy, 2nd ed., Wiley, 2007.

21 R. K. H. Galvao, S. Hadjiloucas, A. Zafiropoulos, G. C. Walker, J. W. Bowen and R. Dudley, Opt. Lett., 2007, 32, 3008-3010.

22 R. B. Blackman and J. W. Tukey, The Measurement of Power Spectra, From the Point of View of Communications Engineering, Dover, 1959.

23 J. O. Smith, Mathematics of the Discrete Fourier Transform (DFT), with Audio Applications, 2nd ed., W3K Publishing, 2007.

24 M. J. Frisch, G. W. Trucks, H. B. Schlegel, G. E. Scuseria, M. A. Robb, J. R. Cheeseman, G. Scalmani, V. Barone, B. Mennucci, G. A. Petersson, H. Nakatsuji, M. Caricato, X. Li, H. P. Hratchian, A. F. Izmaylov, J. Bloino, G. Zheng, J. L. Sonnenberg, M. Hada, M. Ehara, K. Toyota, R. Fukuda, J. Hasegawa, M. Ishida, T. Nakajima, Y. Honda, O. Kitao, H. Nakai, T. Vreven, J. A. Montgomery, Jr., J. E. Peralta, F. Ogliaro, M. Bearpark, J. J. Heyd, E. Brothers, K. N. Kudin, V. N. Staroverov, R. Kobayashi, J. Normand, K. Raghavachari, A. Rendell, J. C. Burant, S. S. Iyengar, J. Tomasi, M. Cossi, N. Rega, J. M. Millam, M. Klene, J. E. Knox, J. B. Cross, V. Bakken, C. Adamo, J. Jaramillo, R. Gomperts, R. E. Stratmann, O. Yazyev, A. J. Austin, R. Cammi, C. Pomelli, J. W. Ochterski, R. L. Martin, K. Morokuma, V. G. Zakrzewski, G. A. Voth, P. Salvador, J. J. Dannenberg, S. Dapprich, A. D. Daniels, FarkasJ. B. Foresman, J. V. Ortiz, J. Cioslowski and D. J. Fox, Gaussian 09 Revision D.01, Gaussian Inc., Wallingford CT, 2009.

25 C. J. Cramer, Essentials of Computational Chemistry, 2nd ed., Wiley, 2004.

26 J. A. Pople, A. P. Scott, M. W. Wong and L. Radom, Isr. J. Chem., 1993, 33, 345350. 
27 A. H. Hardin and K. B. Harvey, Spectrochim. Acta, Part A, 1973, 29, 11391151.

28 G. A. Baratta, G. Leto, F. Spinella, G. Strazzulla and G. Foti, Astron. Astrophys., 1991, 252, 421-424.

29 P. Jenniskens, S. F. Banham, D. F. Blake and M. R. S. McCoustra, J. Chem. Phys., 1997, 107, 1232-1241.

30 W. Hagen, A. G. G. M. Tielens and J. M. Greenberg, Astron. Astrophys. Suppl. Ser., 1983, 51, 389-416.

31 G. W. Fuchs, H. M. Cuppen, S. Ioppolo, S. E. Bisschop, S. Andersson, E. F. van Dishoeck and H. Linnartz, Astron. Astrophys., 2009, 505, 629.

32 S. E. Bisschop, G. W. Fuchs, A. C. A. Boogert, E. F. van Dishoeck and H. Linnartz, Astron. Astrophys., 2007, 470, 749-759.

33 H. Hollenstein and H. H. Günthard, Spectrochim. Acta, Part A, 1971, 27, 20272060.

34 M. Haurie and A. Novak, Spectrochim. Acta, 1965, 21, 1217-1223.

35 J. E. Bertie and S. M. Jacobs, J. Chem. Phys., 1977, 67, 2445-2448.

36 R. L. Hudson and M. H. Moore, Astrophys. J., 1993, 404, L29-L32.

37 D. M. Hudgins, S. A. Sandford, L. J. Allamandola and A. G. G. M. Tielens, Astrophys. J. Suppl., 1993, 86, 713-870.

38 S. Krishnamurthy, R. Bansil and J. Wiafe-Akenten, J. Chem. Phys., 1983, 79, 5863-5870.

39 G. Profeta and S. Scandolo, Phys. Rev. B: Condens. Matter Mater. Phys., 2011, 84, 024103.

40 T. Shimanouchi, Nat. Stand. Ref. Data Scr., Nat. Bur. Stand. (US), 1972, 39, 1-164.

41 A. C. Cheung, D. M. Rank, C. H. Townes, D. D. Thornton and W. J. Welch, Nature, 1969, 221, 626-628.

42 R. W. Wilson, K. B. Jefferts and A. A. Penzias, Astrophys. J., 1970, 161, L43.

43 J. A. Ball, C. A. Gottlieb, A. E. Lilley and H. E. Radford, Astrophys. J., 1970, 162, L203.

44 B. Zuckerman, J. A. Ball and C. A. Gottlieb, Astrophys. J., 1971, 163, L41.

45 N. Fourikis, M. W. Sinclair, B. J. Robinson, P. D. Godfrey and R. D. Brown, Australian Journal of Physics, 1974, 27, 425.

46 W. Gilmore, M. Morris, P. Palmer, D. R. Johnson, F. J. Lovas, B. E. Turner and B. Zuckerman, Astrophys. J., 1976, 204, 43-46.

47 D. M. Mehringer, L. E. Snyder, Y. Miao and F. J. Lovas, Astrophys. J., 1997, 480, L71.

48 F. Combes, M. Gerin, A. Wootten, G. Wlodarczak, F. Clausset and P. J. Encrenaz, Astron. Astrophys., 1987, 180, L13-L16.

49 E. F. van Dishoeck, E. Herbst and D. A. Neufeld, Chem. Rev., 2013, 113, 90439085.

50 N. Watanabe and A. Kouchi, Astrophys. J., 2002, 571, L173-L176.

51 S. Ioppolo, H. M. Cuppen, E. F. van Dishoeck and H. Linnartz, Mon. Not. R. Astron. Soc., 2011, 410, 1089-1095.

52 S. E. Bisschop, G. W. Fuchs, E. F. van Dishoeck and H. Linnartz, Astron. Astrophys., 2007, 474, 1061-1071.

53 W. A. Schutte, J. M. Greenberg, E. F. van Dishoeck, A. G. G. M. Tielens, A. C. A. Boogert and D. C. B. Whittet, Astrophysics and Space Science, 1998, 255, 61-66. 
54 W. A. Schutte, A. C. A. Boogert, A. G. G. M. Tielens, D. C. B. Whittet, P. A. Gerakines, J. E. Chiar, P. Ehrenfreund, J. M. Greenberg, E. F. van Dishoeck and T. de Graauw, Astron. Astrophys., 1999, 343, 966-976.

55 E. L. Gibb, D. C. B. Whittet, A. C. A. Boogert and A. G. G. M. Tielens, Astrophys. J. Suppl., 2004, 151, 35-73.

56 J. V. Keane, A. G. G. M. Tielens, A. C. A. Boogert, W. A. Schutte and D. C. B. Whittet, Astron. Astrophys., 2001, 376, 254-270. 